\title{
Evaluation of video-based linear depth inversion performance and applications using altimeters and hydrographic surveys in a wide range of environmental conditions
}

\author{
Katherine L. Brodie ${ }^{a, *}$, Margaret L. Palmsten ${ }^{b}$, Tyler J. Hesser ${ }^{c}$, Patrick J. Dickhudt ${ }^{a}$, \\ Britt Raubenheimer ${ }^{\mathrm{d}}$, Hannah Ladner ${ }^{\mathrm{b}}$, Steve Elgar ${ }^{\mathrm{d}}$ \\ ${ }^{a}$ Coastal and Hydraulics Laboratory, US Army Engineer Research and Development Center, 1261, Duck Rd, Duck, NC, United States \\ ${ }^{\mathrm{b}}$ Marine Geosciences Division, Naval Research Laboratory, Stennis Space Center, MS, United States \\ ${ }^{\mathrm{c}}$ Coastal and Hydraulics Laboratory, US Army Engineer Research and Development Center, Coastal and Hydraulics Laboratory, 3909, Halls Ferry Rd, Vicksburg, MS, \\ United States \\ ${ }^{\mathrm{d}}$ Woods Hole Oceanographic Institution, 266 Woods Hole Rd., Woods Hole, MA, United States
}

\section{A R T I C L E I N F O}

\section{Keywords:}

Remote sensing

Beach morphology

Depth inversion

Bathymetry estimation

Video imaging

Surfzone

\begin{abstract}
A B S T R A C T
The performance of a linear depth inversion algorithm, cBathy, applied to coastal video imagery was assessed using observations of water depth from vessel-based hydrographic surveys and in-situ altimeters for a wide range of wave conditions $(0.3<$ significant wave height $<4.3 \mathrm{~m})$ on a sandy Atlantic Ocean beach near Duck, North Carolina. Comparisons of video-based cBathy bathymetry with surveyed bathymetry were similar to previous studies (root mean square error $(\mathrm{RMSE})=0.75 \mathrm{~m}$, bias $=-0.26 \mathrm{~m}$ ). However, the cross-shore locations of the surfzone sandbar in video-derived bathymetry were biased onshore $18-40 \mathrm{~m}$ relative to the survey when offshore wave heights exceeded $1.2 \mathrm{~m}$ or were greater than half of the bar crest depth, and broke over the sandbar. The onshore bias was 3-4 m when wave heights were less than $0.8 \mathrm{~m}$ and were not breaking over the sandbar. Comparisons of video-derived seafloor elevations with in-situ altimeter data at three locations onshore of, near, and offshore of the surfzone sandbar over $\sim 1$ year provide the first assessment of the cBathy technique over a wide range of wave conditions. In the outer surf zone, video-derived results were consistent with long-term patterns of bathymetric change $\left(r^{2}=0.64\right.$, RMSE $=0.26 \mathrm{~m}$, bias $\left.=-0.01 \mathrm{~m}\right)$, particularly when wave heights were less than $1.2 \mathrm{~m}\left(r^{2}=0.83\right)$. However, during storms when wave heights exceeded $3 \mathrm{~m}$, video-based cBathy over-estimated the depth by up to $2 \mathrm{~m}$. Near the sandbar, the sign of depth errors depended on the location relative to wave breaking, with video-based depths overestimated (underestimated) offshore (onshore) of wave breaking in the surfzone. Wave speeds estimated by video-based cBathy at the initiation of wave breaking often were twice the speeds predicted by linear theory, and up to three times faster than linear theory during storms. Estimated wave speeds were half as fast as linear theory predictions at the termination of wave breaking shoreward of the sandbar. These results suggest that video-based cBathy should not be used to track the migration of the surfzone sandbar using data when waves are breaking over the bar nor to quantify morphological evolution during storms. However, these results show that during low energy conditions, cBathy estimates could be used to quantify seasonal patterns of seafloor evolution.
\end{abstract}

\section{Introduction}

Accurate observations of surfzone bathymetry are critical to simulating nearshore waves and currents and the subsequent sediment transport and morphological change, as well as storm-induced overtopping and flooding. Vessel-based acoustic hydrographic surveys provide temporally infrequent, but spatially dense data, whereas in-situ acoustic altimeters provide temporally dense, but spatially sparse observations of seafloor elevation (Moulton et al., 2014). Both acoustic techniques provide bathymetric data with errors on the order of $0.1 \mathrm{~m}$ across the surf zone. Depth inversion methods using optical, infrared, and radar imagery estimate bathymetry from wave speed observations with

\footnotetext{
* Corresponding author.

E-mail address: Katherine.L.Brodie@usace.army.mil (K.L. Brodie).
} 
high spatial and temporal resolution (Holman et al., 2013), but accuracy over a range of environmental conditions is not well quantified. Although in development for more than 20 years, remote sensing methods rarely have been used in applied coastal engineering projects to quantify surfzone bathymetry, and initial tests to calculate surfzone sediment volumes have poor skill (Rutten et al., 2017). A potential application is to use the data as boundary conditions for numerical models of surfzone processes (Radermacher et al., 2014; Díaz Méndez et al., 2015; Smith et al., 2017). For example, using remotely sensed data to estimate the position of the sandbar in a surfzone bathymetric grid significantly increases the fidelity of numerical simulations of surfzone circulation (Holman et al., 2014; Wilson et al., 2014). Another application is to use the data to track sediment exchange between the beach and surfzone sandbar for regional sediment management (Moritz et al., 2007). Improved assessment of algorithm skill in a wide range of environmental conditions, and evaluation of the ability of remote-sensing-based bathymetry estimation techniques to quantify surfzone sandbar morphology and seafloor evolution through time are needed for practical implementation in coastal engineering.

Optical nearshore remote sensing techniques exploit the image signature of shoaling and breaking surface gravity waves in the surf zone (Holman and Stanley, 2007). The morphology of surfzone sandbars can be estimated qualitatively from time-averages of pixel-intensities that map where waves break (Lippmann and Holman, 1990; Alexander and Holman, 2004). In addition, surfzone bathymetry can be estimated quantitatively from time-averaged images of wave breaking (a proxy for wave dissipation) that are assimilated into numerical models that solve for water depth (Aarninkhof et al., 2005; van Dongeren et al., 2008), as well as from wave speeds estimated from the video imagery using either linear (Stockdon and Holman, 2000; Dugan et al., 2001a) or nonlinear (Holland, 2001; Catálan and Haller, 2008) dispersion relationships.

The cBathy algorithm (Holman et al., 2013) requires a time series of imagery of waves in intermediate and shallow water to estimate depth. The algorithm combines cross-spectral phase measurements with a weighted nonlinear least-squares solution to the linear dispersion equation (Plant et al., 2008). The temporal evolution of cBathy-estimated bathymetry is smoothed with a time-averaging Kalman filter based on present and prior bathymetric estimates along with uncertainty estimated from the least squares fit. Video-based cBathy bathymetry estimates have been compared with vessel-based bathymetry surveys for a range of beaches (Table 1), but rarely with waves bigger than $1.7 \mathrm{~m}$, and never for waves bigger than $2.0 \mathrm{~m}$ because of the difficulty of performing in-situ surveys in the presence of large waves. Root mean square differences between cBathy-estimated and surveyed seafloor elevations in previous studies range between 0.51 and $2.05 \mathrm{~m}$ (Table 1, (Holman et al., 2013; Rutten et al., 2017; Radermacher et al., 2014; Holman and Stanley, 2013; Wengrove and Henriquez, 2013; Bergsma et al., 2016)). Errors frequently are largest in shallow water near the shoreline, where (1) linear theory may not be valid; (2) the rapid cross-shore depth changes (over a cBathy sample domain or smoothing distance) cannot be resolved; and (3) wave speed estimates can be distorted by wave runup. Errors in cBathy depth estimates are correlated with wave height and water depth in some locations (Holman et al., 2013). cBathy estimated uncertainties may be related to observed errors, but are often too small in magnitude (Holman et al., 2013), and have not been evaluated during storms.

Sources of error in cBathy include inaccurate parameter extraction from the imagery data and inaccurate representation of the physics (e.g., environmental conditions outside of the algorithm assumptions). For example, the linear dispersion relationship may be inaccurate as waves shoal and break in the surf zone, underestimating wave speeds by 20-40\% (Holland, 2001; Catálan and Haller, 2008; Guza and Thornton, 1980; Thornton and Guza, 1982; Elgar and Guza, 1985a; Okamoto et al., 2010). The implementation of linear theory in (Holman et al., 2013) may be inaccurate as waves shoal and become nonlinear, as well as near the shoreline as waves break and transition to swash (Inman et al., 1971; Suhayda and Pettigrew, 1977). Incorporating wave nonlinearity into bathymetric inversions from wave speed reduced errors inside the breakpoint to $\mathrm{O}(10 \%)$ in a laboratory study (Catálan and Haller, 2008), similar to the performance of linear wave theory outside the surf zone. The performance of cBathy when wave height exceeds $2 \mathrm{~m}$ has not been evaluated, and thus, it is unclear how errors in the estimated phase speeds of nonlinear waves breaking over the sandbar affect the estimation of the bathymetry.

Here, new field measurements are used to assess video-based cBathy estimates of the position and movement of nearshore sandbars and of seabed elevation changes over seasonal time-scales for a large range of wave conditions $\left(0.3<H_{s}<4.6 \mathrm{~m}\right.$, where the significant wave height $H_{s}$ is defined as 4 times the standard deviation of sea-surface-elevation fluctuations) on a micro-tidal ocean beach. The bathymetry was surveyed frequently over a large area with vessel-based systems, and seabed elevation was measured nearly continuously over a year at three nearshore locations with in-situ altimeters. The high-spatial resolution vesselbased surveys were used to assess the ability of video-derived bathymetry to correctly characterize the sandbar position and elevation, the dominant morphologic feature in many sandy surf zones. The altimeter data were used to assess cBathy's performance both during a range of wave conditions and over long time periods, as well as to assess cBathy's

Table 1

cBathy Performance Statistics From Prior Work, Organized By Decreasing $H_{s}$.

\begin{tabular}{|c|c|c|c|c|c|c|c|c|c|}
\hline Date & $\mathrm{Hs}(\mathrm{m})$ & $\begin{array}{l}\mathrm{Tp} \\
(\mathrm{s})\end{array}$ & $\begin{array}{l}\text { Bias } \\
\text { (m) }\end{array}$ & RMSE (m) & Tide $(\mathrm{m})$ & Location & $\begin{array}{l}\# \\
\text { Obs. }\end{array}$ & Reference & Notes \\
\hline 2009-2011 & $0.25-2.00$ & - & 0.19 & 0.51 & 0.98 & Duck, NC USA & 16 & Holman et al., 2013 & \\
\hline $\begin{array}{l}\text { Mar-2013 to Mar- } \\
2014\end{array}$ & $<1.65$ & - & 0.59 & 0.79 & - & SandEngine Netherlands & 6 & Rutten et al., 2017 & $-10<$ depth $<-5 \mathrm{~m}$ \\
\hline $\begin{array}{l}\text { Mar-2013 to Mar- } \\
2014\end{array}$ & $<1.65$ & - & -0.01 & 0.34 & - & & 6 & & $-5<$ depth $<-1 \mathrm{~m}$ \\
\hline $\begin{array}{l}\text { Mar-2013 to Mar- } \\
2014\end{array}$ & $<1.65$ & - & -0.92 & 0.34 & - & & 6 & & $-1<$ depth $<0 \mathrm{~m}$ \\
\hline 13-Jul-13 & - & 7.1 & -0.41 & 0.56 & $>3$ & Agate Beach, OR, USA & 1 & Holman et al., 2013 & \\
\hline 17-May-12 & 1.19 & $5-7$ & 0 & 0.52 & - & New River Inlet, NC, USA & 1 & Holman and Stanley, 2013 & \\
\hline 10-Apr-14 & 1.16 & 10.5 & - & 1.06 & 2.78 & $\begin{array}{l}\text { Porthtowan, Cornwall, } \\
\text { England }\end{array}$ & 1 & Bergsma et al., 2016 & \\
\hline 20-Feb-13 & 0.64 & 5.8 & -0.18 & 1.01 & $1.4-1.9$ & Kijkduin, Netherlands & 1 & $\begin{array}{l}\text { Wengrove and Henriquez, } \\
2013\end{array}$ & $\widehat{h}_{k}$ results \\
\hline 17-Apr-14 & 0.52 & 10.4 & - & 2.05 & 6.03 & $\begin{array}{l}\text { Porthtowan, Cornwall, } \\
\text { England }\end{array}$ & 1 & Bergsma et al., 2016 & \\
\hline 01 to $04 \mathrm{Jul}-13$ & $<0.50$ & - & - & $0.48-0.66$ & - & SandEngine, Netherlands & 1 & Radermacher et al., 2014 & \\
\hline \multirow[t]{2}{*}{ 17-Feb-13 } & 0.22 & 8.5 & -0.5 & 1.27 & $\begin{array}{l}1.4 \text { to } \\
1.9\end{array}$ & Kijkduin, Netherlands & 1 & $\begin{array}{l}\text { Wengrove and Henriquez, } \\
2013\end{array}$ & $\widehat{h}_{k}$ results \\
\hline & Average: & & -0.26 & 0.91 & & & & & \\
\hline
\end{tabular}


uncertainty estimates. Observed errors and predicted errors were evaluated relative to seafloor elevation, wave height, and wave breaking locations, and a detailed analysis of cBathy's Kalman filter during a storm was used to elucidate the performance of the algorithm during energetic conditions.

\section{Methodology}

Observations of nearshore wave heights, surfzone wave speeds, and surfzone bathymetry were collected on a sandy Atlantic Ocean beach near Duck, North Carolina, USA at the U.S. Army Corps of Engineers (USACE) Field Research Facility (FRF) using a directional wave buoy, remotely-sensed video imagery, amphibious-vessel based hydrographic surveying, and in-situ altimeters. Spatial data are presented in a local cross- and alongshore coordinate system, with origin at $36.1776^{\circ} \mathrm{N}$ and $75.7497^{\circ} \mathrm{W}$ and a rotation of $17.7^{\circ}$ relative to true north (Fig. 1). Eight bathymetric surveys were conducted between 15 Sep and 30 Oct 2015 with a Lighter Amphibious Resupply Cargo (LARC) vessel and the Coastal Research Amphibious Buggy (CRAB). Video, seafloor elevation, and wave data were collected from Sep 2015 through Sep 2016.

\subsection{Wave observations}

Wave data are used to characterize the environmental conditions for each video-derived bathymetry estimate for analysis of performance statistics. Wave conditions were estimated with a Datawell Directional Waverider buoy at CDIP Station 433 in 17-m water depth, where wave heights ranged from 0.3 to $4.3 \mathrm{~m}$ and periods, $T_{p}$ (corresponding to the frequency of the peak of the spectrum), ranged from 4 to $18 \mathrm{~s}$ over the 12month period (Fig. 2). The observations included six storms with significant wave height, $H_{s},>3 \mathrm{~m}$, two of which had $H_{s}>4 \mathrm{~m}$ (Fig. 2A). Between 15 Sep and 30 Oct 2015, frequent vessel-based surveys were conducted to quantify surf-zone morphology evolution (see section 2.3). Both a nor'easter and a tropical system influenced the wave conditions during this focused data collection period. From 20 Sep to 01 Oct $H_{s}$ exceeded $2 \mathrm{~m}$ (blue curve, Fig. 2B), and $T_{p}$ ranged from 8 to $10 \mathrm{~s}$ (red dots, Fig. 2B). From 04 to 07 Oct, Hurricane Joaquin passed offshore, generating long period swell $\left(H_{s}>4 \mathrm{~m}, 10<T_{p}<13 \mathrm{~s}\right)$. From 08 to 26 Oct the wave climate was a mix of smaller $\left(H_{s}<1 \mathrm{~m}\right)$ sea and swell $\left(4<T_{p}<13 \mathrm{~s}\right)$, and from 26 to 30 Oct there were waves from the northeast with $H_{s} \sim 2 \mathrm{~m}$ (Fig. 2B).

\subsection{Video imaging}

Video images of the nearshore region (Fig. 1) were obtained with an Argus coastal monitoring station (Holman and Stanley, 2007) located $43 \mathrm{~m}$ above mean sea level on a tower. Time-averages (10-min) of pixel intensity at the start of each half-hour (Fig. 1) were used to identify locations of wave breaking during the experiment. Time-series $(2 \mathrm{~Hz}$ sample rate for $17 \mathrm{~min}$ every half hour) at a sub-set of pixels, with a spatial resolution of 5 and $10 \mathrm{~m}$ in the cross- and alongshore directions, respectively, were used to estimate frequency and wave number over the $800 \mathrm{~m}$ cross-shore by $1500 \mathrm{~m}$ alongshore analysis domain. The video estimates of frequency and wave number were converted to water depth via the linear dispersion relation using the cBathy algorithm (Holman et al., 2013) with a spatial resolution of 10 and $25 \mathrm{~m}$ in the cross- and

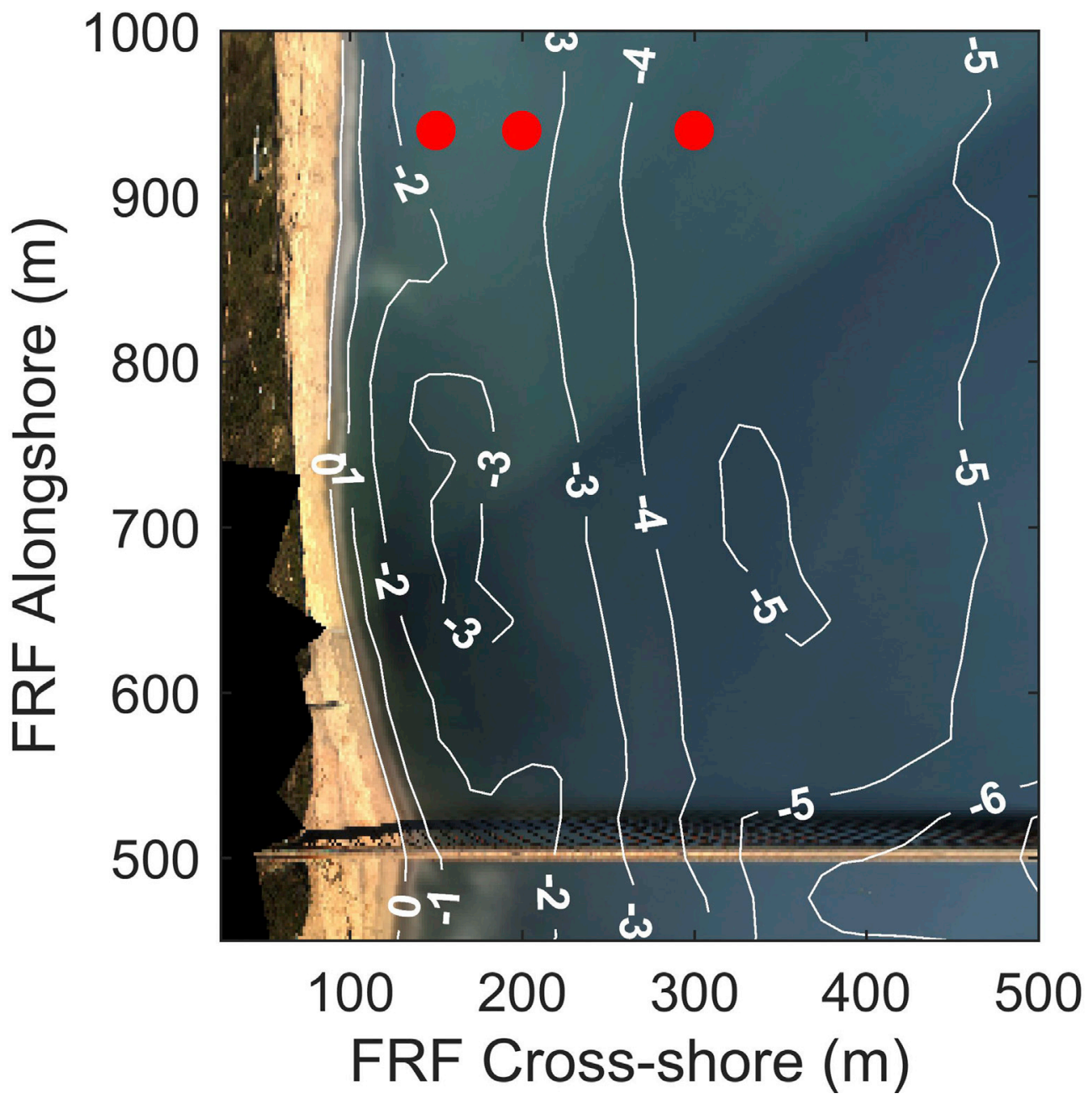

Fig. 1. Argus video time-average (10 $\mathrm{min})$ imagery rectified into the FRF local coordinate system from 15 Sep 2015 with location of the 3 altimeters (red dots), and 1-m contour intervals (white curves are seafloor elevation relative to NAVD88) of the corresponding gridded bathymetric survey. The FRF pier is the beige colored horizontal feature at $516 \mathrm{~m}$ alongshore that extends across the width of the image. (For interpretation of the references to color in this figure legend, the reader is referred to the Web version of this article.) 


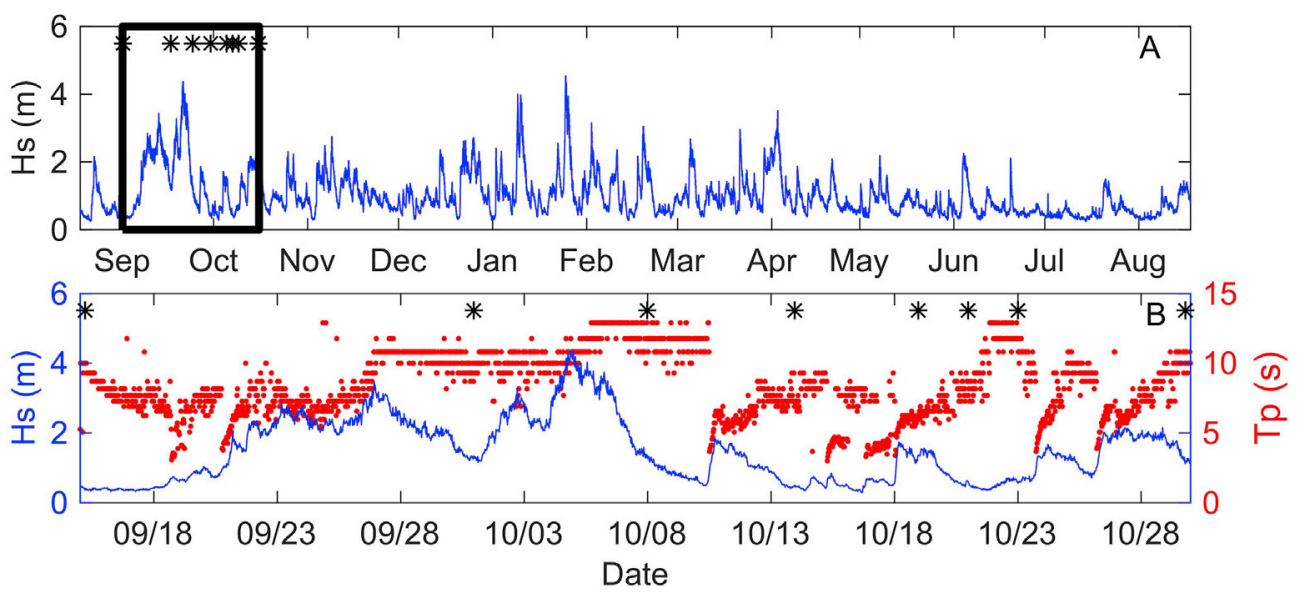

Fig. 2. 17-m water depth (A) significant wave height $\left(\mathrm{H}_{\mathrm{s}}\right)$ and (B) significant wave height $\left(\mathrm{H}_{\mathrm{s}}\right.$, blue curve, left axis) and peak period $\left(\mathrm{T}_{\mathrm{p}}\right.$, red dots, right axis) versus time. The black box in (A) identifies the times shown in (B), which correspond to the data observed during and between the vesselbased surveys (survey times indicated with asterisks). (For interpretation of the references to color in this figure legend, the reader is referred to the Web version of this article.) alongshore. Thus, bathymetric variability with length scales greater than $\sim 10$ times the water depth are resolved (Plant et al., 2008). Other sampling parameters matched previous literature (Holman et al., 2013).

The cBathy algorithm (https://github.com/Coastal-ImagingResearch-Network/cBathy-toolbox) consists of three processing steps. In step 1, the wave frequencies in the images are estimated from spectral analysis of the video time series at the sub-set of pixels. Fourier coefficients are normalized to remove intensity differences across the images, and cross-spectra are computed within a 100 (cross-shore) X $200 \mathrm{~m}$ (alongshore) region centered on each cBathy output point. The wave number and direction at each of the four dominant frequencies are estimated from the cross-spectra, and the linear dispersion relationship is used to produce four estimates of the water depth. These initial depth estimates are mostly used for diagnostic purposes.

In step 2 , a single depth estimate, $h_{k}$, at each cBathy output point, $k$, is determined from a nonlinear weighted fit of the four frequency-wave number pairs to the linear dispersion relationship (Plant et al., 2008). The 95\% confidence interval on the weighted nonlinear fit is defined as the measurement error confidence interval, $\varepsilon_{P 2}$ for the step 2 depth estimate. $\varepsilon_{P 2}$ is used to weight $h_{k}$ in the final Kalman filtered depth estimate, as described below. The depth $h_{k}$ is subtracted from the measured tide level to estimate the seafloor elevation, $\widehat{h}_{k}$.

In step 3, a Kalman Filter is used to compute the weighted running average in time of the potentially noisy $\widehat{h}_{k}$. Success of the Kalman filtering step depends on accurate representation of the process and measurement noise variances (Kalman, 1960). Here, the smoothed seafloor elevation $\widehat{h}_{k}$ depends on the previous estimate of bathymetry at that location, $\bar{h}_{k-1}$, the new bathymetry estimate from step $2, \widehat{h}_{k}$, and the Kalman gain, $K$, as

$\bar{h}_{k}=\bar{h}_{k-1}+K\left(\widehat{h}_{k}-\bar{h}_{k-1}\right)$,

where $K$ is given by

$K=\frac{P_{k}^{-}}{P_{k}^{-}+R}$,

where $R=\left(\varepsilon_{P 2}\right)^{2}$ is the measurement error variance, and $P_{k}^{-}$, is the prior estimate of error variance updated from the previous time step, given by

$P_{k}^{-}=P_{k-1}+Q \Delta t$,

where $Q$ is the process noise covariance, and quantifies the expected daily bathymetric variability, and $\Delta t$ is the time interval between estimates. The process noise covariance, $Q$, used here was derived empirically this site (Holman et al., 2013), and varies temporally and spatially with wave height and cross-shore position, respectively. The posterior error variance, $P_{k}$ is updated as

$P_{k}=(1-K) P_{k}^{-}$,

Equations (1)-(4) produce the best estimate of bathymetry from the cBathy algorithm, $\bar{h}_{k}$, and an associated estimated error, $\varepsilon_{P 3}=\sqrt{P_{k}}$ (Holman et al., 2013). $\bar{h}_{k}$ and $\varepsilon_{P 3}$ thus provide a seafloor elevation and confidence interval that can be thought of as a probabilistic estimate of the bathymetry at each time-step. True error should fall between the depth estimate and $\pm \varepsilon_{P 3} 95 \%$ of the time. Prior work suggests $\varepsilon_{P 3}$ may be too small by a factor of seven, but that it may be related to the true error (Holman et al., 2013). The Kalman filter is used as a smart smoothing tool that reduces the effect of poor quality $\widehat{h}_{k}$ based on $\varepsilon_{P 2}$, and thus no additional quality checks were performed on the cBathy results (Holman et al., 2013).

\subsection{Vessel-based hydrographic surveys}

Vessel-based hydrographic surveys using real time kinematic (RTK)GPS and acoustic sensors mounted on amphibious vehicles and watercraft (Birkemeier and Mason, 1984; Dugan et al., 2001b; MacMahan, 2001) quantify seafloor bathymetry at high spatial resolution (hong Lee et al., 1998; Ludka et al., 2015; Ruggiero et al., 2016) during mild conditions. Here, hydrographic surveys complement the continuously sampled, but spatially sparse, altimeter observations (Section 2.4).

Six bathymetric surveys were performed (asterisks, Fig. 2) with the Coastal Research Amphibious Buggy (CRAB) (01, 08, 16, 19, 23, 30 Oct) and two with the Lighter Amphibious Resupply Cargo (LARC) vessel (15 Sep and 21 Oct). The CRAB is a $10.7 \mathrm{~m}$ tall amphibious wheeled tripod that drives along the seafloor and measures topography and bathymetry across the surf zone (Birkemeier and Mason, 1984) approximately every $1 \mathrm{~m}$ with a vertical accuracy of $0.03 \mathrm{~m}$ (Lee and Birkemeier, 1993). The LARC is a $10.7-\mathrm{m}$ long amphibious vessel that measures bathymetry roughly every $2 \mathrm{~m}$ with a vertical accuracy of $0.05 \mathrm{~m}$ (Dugan et al., 1999). The surveys were conducted along cross-shore transects spaced $25 \mathrm{~m}$ alongshore between 500 and $1000 \mathrm{~m}$ alongshore (Fig. 1), except on 15 Sep when the alongshore spacing was $50 \mathrm{~m}$. On 01 October, only a partial survey $(875<$ alongshore $<1000 \mathrm{~m}$ ) was completed owing to rapidly increasing wave heights. The survey data were gridded to match the cBathy analysis points using scale-controlled interpolation (Plant et al., 2002) with a smoothing length scale equivalent to the smoothing length scale in the cBathy algorithm.

\subsection{Altimeters}

Acoustic altimeters measure seafloor elevation with order $0.1 \mathrm{~m}$ accuracy at high temporal resolution (Moulton et al., 2014; Gallagher et al., 
1996). Here, three altimeters were deployed across the nearshore region at cross-shore distances 150,200 , and $300 \mathrm{~m}$ in the local coordinate system (Fig. 1) and are referred to as the inner, middle, and outer altimeters, respectively. To ensure a stable platform capable of withstanding strong storms without significant motion or damage, the altimeters were mounted to heavy, $0.05 \mathrm{~m}$ diameter, round pipes jetted $\sim 4.5 \mathrm{~m}$ into the seafloor. Armored cable provided power, instrument control, and real-time data collection. The sensors were not power or memory limited and were designed to collect long-term observations. The inner and middle altimeters were installed at the end of September 2015, and the outer altimeter was installed in late October 2015. Data from these altimeters were analyzed through the end of September 2016. The elevation of the altimeters relative to NAVD88 was determined to within $0.04 \mathrm{~m}$ with RTK-GPS using corrections from a local base station.

The altimeters provided nearly continuous observations of seafloor elevation across the sandbar for $\sim 1$ year with $0.25<\mathrm{H}_{\mathrm{s}}<4.3 \mathrm{~m}$ (Fig. 2A). The altimeters report acoustic backscatter intensity at $1 \mathrm{~Hz}$ every $0.0075 \mathrm{~m}$ over a $3.5 \mathrm{~m}$ vertical profile. Bottom-finding algorithms estimated the location of the seafloor from the profiles of acoustic backscatter. During optimal conditions, the seafloor was identified using
2-5 min of observations, whereas during energetic conditions $\left(H_{s}>3 \mathrm{~m}\right)$ up to $1 \mathrm{~h}$ of data was required to identify the seafloor because bubbles and suspended sediments resulted in a low signal to noise ratio. Except during the largest events $\left(H_{s}>4 \mathrm{~m}\right.$, when the seafloor was in some places obscured for as long as $45 \mathrm{~h}$ ), the seafloor elevation was identified numerous times throughout storms. Thus, the altimeters quantify bathymetry continuously during a wide range of conditions, including during storms when significant bathymetric changes occur (Moulton et al., 2014; Gallagher et al., 1996).

\subsection{Sandbar position extraction from surveys}

Surfzone sandbars are large morphologic features that impact surfzone hydrodynamics and evolve through time as a result of complex cross and alongshore sediment transport patterns. Many applications in coastal processes research and operational coastal engineering require knowledge of the position and elevation of the surfzone sandbar. To evaluate the ability of the video-derived bathymetry to quantify the morphology of the surfzone sandbar, an algorithm was developed to extract the crossshore location $x_{S B}$ and elevation $z_{S B}$ of the sandbar crest from the survey
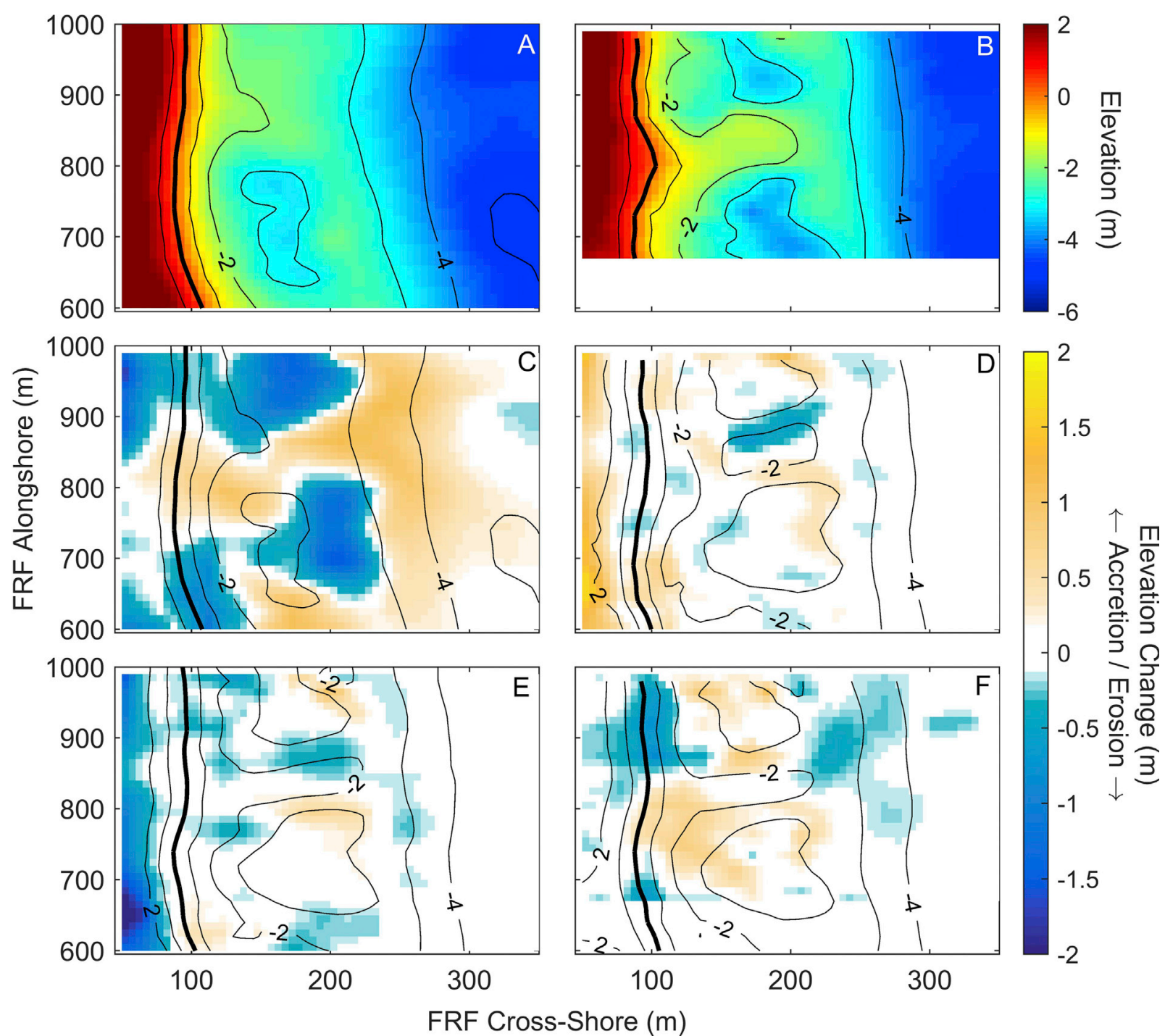

FRF Cross-Shore $(\mathrm{m})$

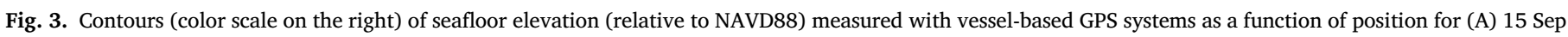

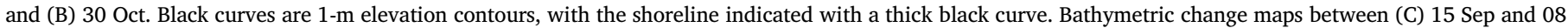

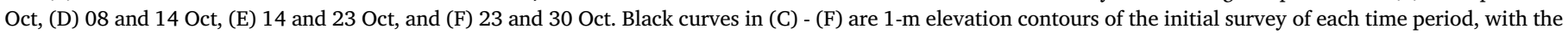

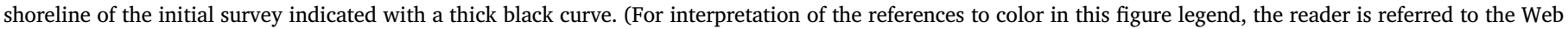
version of this article.) 

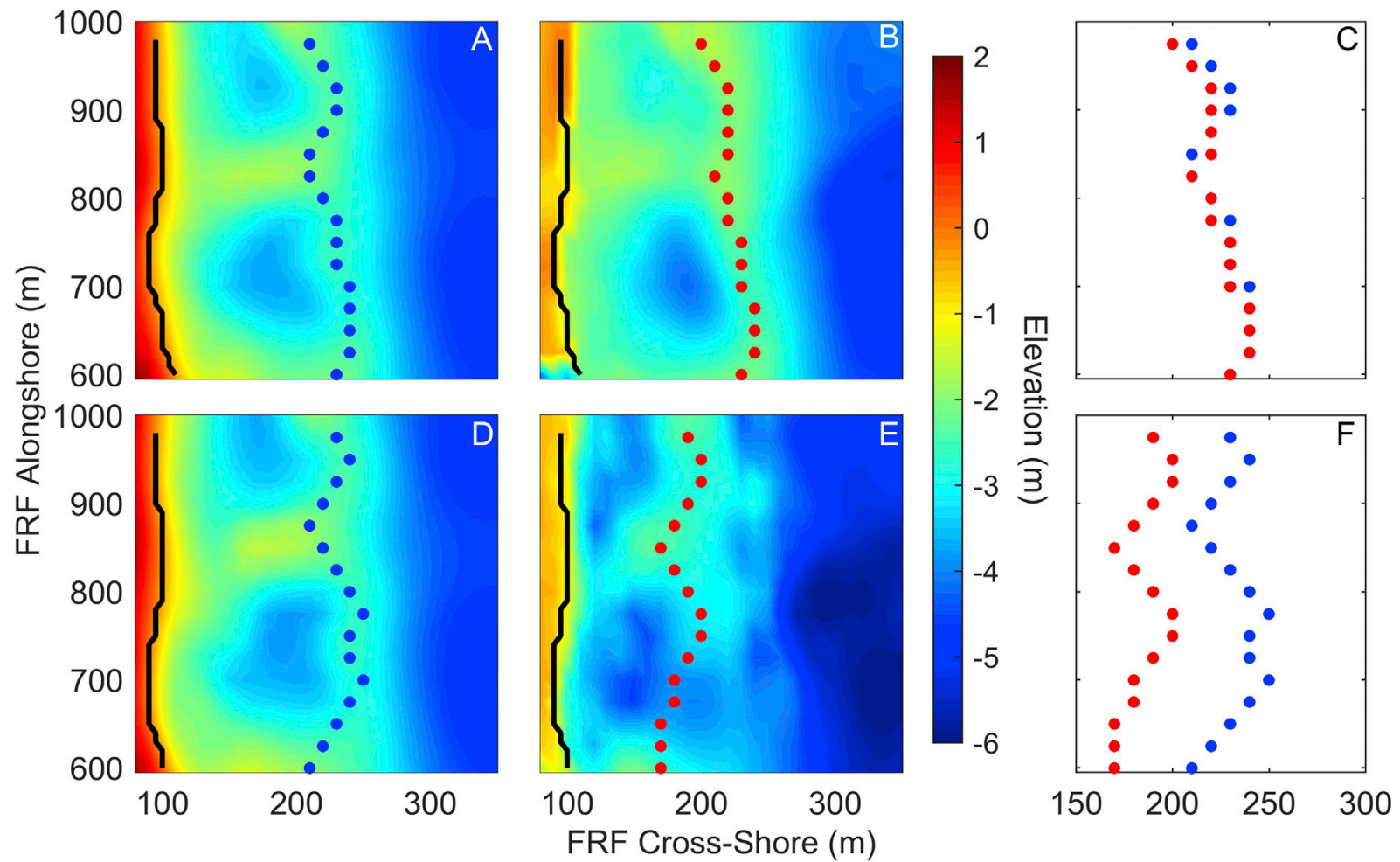

Fig. 4. Contours (color scale on the right) of seafloor elevation (relative to NAVD88) as a function of position for (A, D) Kalman-filtered cBathy $\left(\bar{h}_{k}\right)$ and (B, E) surveyed bathymetry. The filled circles are the location of the sandbar crest. (C,F) Sandbar crest locations estimated with cBathy (blue circles) and with surveys (red circles). (A-C) are for 23 Oct $\left(H_{s}=0.8 \mathrm{~m}\right)$ and (D-F) are for 08 Oct $\left(H_{s}=1.2 \mathrm{~m}\right)$. The shoreline is indicated with a thick black curve (A, B, D, E). (For interpretation of the references to color in this figure legend, the reader is referred to the Web version of this article.)

Table 2

cBathy and Survey Depth, Sandbar, and Error Comparison Statistics, Organized By Decreasing Hs.

\begin{tabular}{|c|c|c|c|c|c|c|c|c|c|c|c|c|}
\hline & Survey Date & $H_{s}(\mathrm{~m})$ & $\begin{array}{l}T_{p} \\
\text { (s) }\end{array}$ & $\begin{array}{l}\widehat{h}_{k} \\
\text { Bias (m) }\end{array}$ & $\begin{array}{l}\widehat{h}_{k} \\
\operatorname{RMSE}(\mathrm{m})\end{array}$ & $\begin{array}{l}\bar{h}_{k} \\
\text { Bias (m) }\end{array}$ & $\begin{array}{l}\bar{h}_{k} \\
\operatorname{RMSE}(\mathrm{m})\end{array}$ & $\begin{array}{l}x_{S B} \\
\text { Bias (m) }\end{array}$ & $\begin{array}{l}x_{S B} \\
\operatorname{RMSE}(\mathrm{m})\end{array}$ & $\begin{array}{l}z_{S B} \\
\text { Bias (m) }\end{array}$ & $\begin{array}{l}z_{S B} \\
\operatorname{RMSE}(\mathrm{m})\end{array}$ & $\gamma=H_{s} / z_{S B}$ \\
\hline \multirow[t]{4}{*}{$H_{s}>1.2 \mathrm{~m}$} & $10 / 1 / 2015$ & 2.00 & 10.00 & -1.58 & 2.35 & -0.38 & 0.68 & 17.50 & 18.02 & 0.10 & 0.13 & 0.93 \\
\hline & $10 / 19 / 2015$ & 1.60 & 6.50 & -0.96 & 1.75 & -0.43 & 0.84 & 25.30 & 26.00 & 0.25 & 0.28 & 0.68 \\
\hline & $10 / 30 / 2015$ & 1.40 & 10.00 & -1.03 & 1.83 & -0.41 & 0.63 & 40.00 & 40.80 & -0.24 & 0.36 & 0.57 \\
\hline & $10 / 8 / 2015$ & 1.21 & 10.80 & -1.10 & 2.43 & -0.70 & 0.93 & 29.40 & 30.70 & -0.68 & 0.81 & 0.51 \\
\hline \multirow[t]{4}{*}{$H_{s}<1.2 \mathrm{~m}$} & $10 / 14 / 2015$ & 0.80 & 8.00 & 0.02 & 0.51 & -0.05 & 0.66 & 2.70 & 16.20 & -0.44 & 0.65 & 0.34 \\
\hline & $10 / 23 / 2015$ & 0.75 & 10.80 & -0.25 & 0.89 & -0.08 & 0.67 & 2.90 & 6.40 & -0.01 & 0.30 & 0.32 \\
\hline & $10 / 21 / 2015$ & 0.40 & 8.10 & 0.25 & 0.61 & 0.22 & 0.81 & 4.10 & 7.10 & 0.28 & 0.45 & 0.18 \\
\hline & & & Mean & -1.17 & 2.09 & -0.48 & 0.77 & 28.05 & 28.88 & -0.14 & 0.40 & \\
\hline
\end{tabular}

Table 3

cBathy and Altimeter Comparison Statistics.

\begin{tabular}{llllllll}
\hline & Bias $(\mathrm{m})$ & RMSE $(\mathrm{m})$ & $r_{\text {seafloor }}^{2}$ & $\sigma_{\text {seafoor }}$ Altimeter $(\mathrm{m})$ & $\sigma_{\text {seafloor }}$ cBathy $(\mathrm{m})$ & $Z_{\text {range }}$ Altimeter $(\mathrm{m})$ & $Z_{\text {range }}$ cBathy $(\mathrm{m})$ \\
\hline Inner & -0.33 & 0.49 & 0.26 & 0.31 & 0.54 & 1.76 & 5.10 \\
Middle & 0.22 & 0.52 & 0.34 & 0.50 & 0.59 & 0.74 & 1.79 \\
Outer & -0.01 & 0.39 & 0.64 & 0.58 & 0.69 & 4.22 & \\
Combined & 0.04 & 0.50 & 0.51 & 0.58 & 5.16 & 53 \\
\hline
\end{tabular}

and also from the corresponding cBathy estimates $\widehat{h}_{k}$ and $\bar{h}_{k}$. The sandbar algorithm was initialized using a manual identification of the location of the sandbar crest every 10-m in the alongshore in both vesselbased and cBathy bathymetries from 15 Sep. This approximate crest location was used to define a Gaussian-shaped region $\pm 200 \mathrm{~m}$ crossshore from the initial estimate, from which the cross-shore crest location $x_{S B}$ was identified using a two-stage dynamic programming (TSDP) technique (Sun, 2002). Subsequent sandbar positions were determined by applying the TSDP to the Gaussian region centered at the previous survey's sandbar position. Sandbar crest elevation $z_{S B}$ was defined as the seafloor elevation at the respective $x_{S B}$ for the survey and for the video-derived bathymetry. $z_{S B}$ from the surveyed data was used to calculate the ratio of offshore wave height to bar crest depth, $\gamma_{\text {off }}=$ $H_{s} / z_{S B .}$, a non-dimensional parameter that may indicate wave breaking is occurring on or offshore of the bar. Prior research at this site suggests that wave breaking occurs when the local wave height to water depth ratio is $>0.42$ (Sallenger and Holman, 1985; Raubenheimer et al., 1996). 


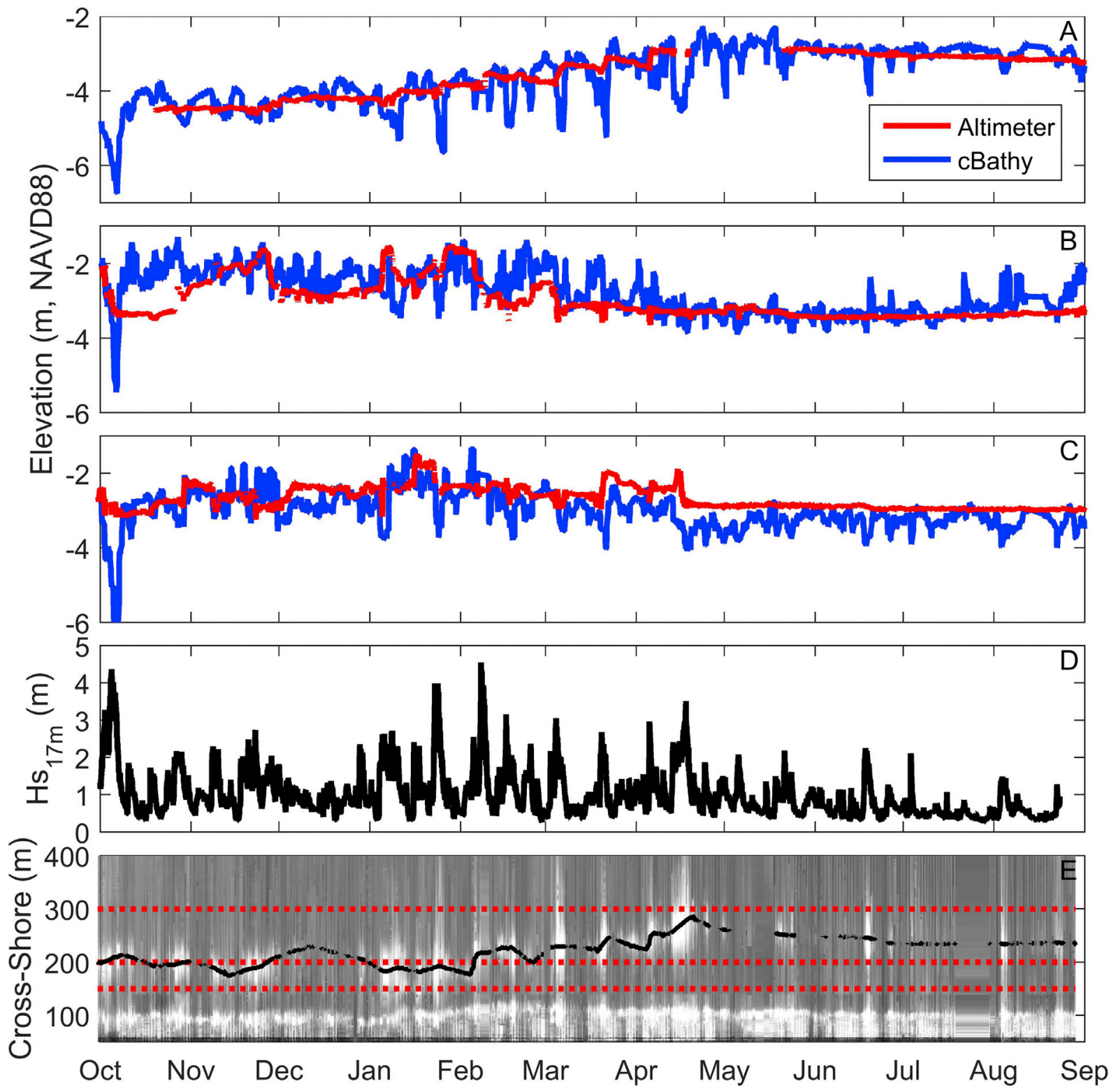

Fig. 5. Seafloor elevation estimated with altimeters (red curves) and with Kalman filtered cBathy (blue curves) in the (A) outer-, (B) mid-, and (C) inner-surf zone, and (D) 17-m depth significant wave height, and (E) time-averaged video pixel intensities (grey scale) versus time. In (E) the cross-shore locations of the inner-, mid-, and outer-surf zone altimeters $(150,200$, and $300 \mathrm{~m}$, respectively) are given by the dashed red lines, and the location of maximum pixel intensity (a proxy for wave breaking and the crest of the sandbar) is given by the black curve. Gaps in the red curves in (A) - (C) occur when the sensor was buried, or when the bottom finding algorithm could not identify the seafloor. (For interpretation of the references to color in this figure legend, the reader is referred to the Web version of this article.)

\subsection{Surfzone sandbar locations \& wave breaking over 1 year}

The 10-min averaged video timex data provide half-hourly observations of locations of persistent wave breaking in the surfzone (see section 2.1 above), identified by high intensity or white pixels, that can be used as a proxy for sandbar morphology (Lippmann and Holman, 1989, 1990; Alexander and Holman, 2004). The cross-shore location of the surf-zone peak in image intensity (whiteness), $x_{\text {break }}$, assumed to be near the crest of the sandbar, was estimated from the half-hourly video timex images along the altimeter transect over the course of a year. The timex transect data were analyzed using the TSDP technique to find a global maximum in image intensities through time. Although the true location of the sandbar crest can be offset from $x_{\text {break }}$ (van Enckevort and Ruessink, 2001), $x_{\text {break }}$ is used here as a proxy for the location of the sandbar, allowing the onshore and offshore migration of the sandbar to be determined over weeks to months. As the sandbar migrated, the middle altimeter at times was onshore of, on, and offshore of the sandbar, allowing quantification of the impacts of wave breaking over the sandbar on the video-derived bathymetry.

\section{Results}

\subsection{Comparison of video-derived bathymetry with vessel-based surveys}

Nearshore bathymetry observed with vessel-based systems and estimated with cBathy was alongshore variable in Sep and Oct 2015 (Figs. 3 and 4). The surveyed bathymetry often included a sandbar, with the bar crest in 1- to 2-m water depth between 200 and $250 \mathrm{~m}$ cross-shore. In Oct the sandbar attached to the shore, creating a narrow terrace between 800 and $875 \mathrm{~m}$ alongshore that was flanked by two 3- to 4-m deep troughs to the north and south (Fig. 3B). These temporal changes in the bathymetry between 15 Sep and 30 Oct (Fig. 3C-F) were related to varying wave 
conditions (Fig. 2). The largest changes occurred between 15 Sep and 08 Oct during the nor'easter and tropical storm systems, with the sandbar migrating $50 \mathrm{~m}$ offshore (Fig. 3A, C). Bathymetric evolution through the rest of Oct was smaller in magnitude, with southern migration $(50 \mathrm{~m})$ of the shore-attached terrace and shoaling of the flanking troughs (Fig. 3DF).

Qualitatively, estimates of $\widehat{h}_{k}$ and $\bar{h}_{k}$ agree with the vessel-based bathymetry estimates, including the development of three-dimensional morphology (crescentic bar, terrace, and flanking troughs) between 15 Sep and 08 Oct, and the persistence of that morphology through the end of Oct (Fig. 4A, D). Quantitatively, the root mean square error (RMSE) and bias of $\widehat{h}_{k}$ relative to the surveys increased with wave height, with $0.51<$ RMSE $<0.89 \mathrm{~m}$ and $-0.25<$ bias $<0.25 \mathrm{~m}$ when $H_{s}<1.2 \mathrm{~m}$, and $1.75<$ RMSE $<2.43 \mathrm{~m}$ and $-1.58<$ bias $<-0.96 \mathrm{~m}$ when $H_{s}>1.2 \mathrm{~m}$ (Table 2 , columns $4 \& 5$ ). In contrast, the RMSE of $\bar{h}_{k}$ relative to the surveys showed no relationship to wave height (Table 2, column 7). However, the bias in $\bar{h}_{k}$ was higher when $H_{s}>1.2 \mathrm{~m}$ (Table 3 , column 6 ). The average RMSE and bias for all survey- $\bar{h}_{k}$ pairs was $0.75 \mathrm{~m}$ and $-0.25 \mathrm{~m}$ respectively, similar to previous results reported at Duck (Holman et al., 2013).

Video-based cBathy sandbar positions identified with the automated algorithm described in section 2.5 (symbols in Fig. 4) qualitatively are consistent with the corresponding surveyed estimates of sandbar position (color contours in Fig. 4A, B, D, E). The RMSE of sandbar location $x_{S B}$ estimated from $\bar{h}_{k}$ relative to the sandbar location estimated from the bathymetric surveys ranged from 6.4 to $40.8 \mathrm{~m}$ and the bias from 2.9 to $40.0 \mathrm{~m}$, all in the onshore direction (Table 2, columns 8 \& 9). Sandbar position biases from $\bar{h}_{k}$ increased with wave height and $\gamma_{\text {off }}$ (Table 2, column 12). When $H_{s}<1.2 \mathrm{~m}$ and $\gamma_{\text {off }}<0.35$, the bias ranged from 2.7 to $4.1 \mathrm{~m}$ and was smaller than the cross-shore resolution of the cBathy solution (Table 2), whereas when $H_{s}>1.2 \mathrm{~m}$ and $\gamma_{\text {off }}>0.5$, the bias ranged from 17.5 to $40.0 \mathrm{~m}$ (Table 2). For example, the video-based cBathy and surveyed sandbar positions are similar for $H_{s}=0.8 \mathrm{~m}$ (Fig. 4C), whereas the video-based cBathy sandbar is biased onshore by $30.7 \mathrm{~m}$ for $H_{s}=1.2 \mathrm{~m}$ (Fig. 4F, Table 3).

\subsection{Comparison of video-derived and altimeter estimates of seafloor elevation}

At the outer altimeter, cBathy estimates of the seafloor elevation, $\bar{h}_{k}$, over the year-long observation period (blue curve, Fig. 5A) are qualitatively similar to altimeter estimates (red curve, Fig. 5A). The altimeterand video-derived seafloor elevation at the outer-surf zone sensor accreted $1.7 \mathrm{~m}$ between Oct and mid-Apr (Fig. 5A). Between mid-May and mid-Sep, the seafloor eroded $0.5 \mathrm{~m}$. The altimeter data suggest that accretion occurred in short bursts corresponding with larger wave events $\left(H_{s}>2 \mathrm{~m}\right)$, followed by gradual erosion during the calmer periods (Fig. 5A red curve \& Fig. 5D). In contrast, when $H_{s}>2 \mathrm{~m}$ (Fig. 5D) and the surf zone was wide (white pixels extending far offshore between Jan and May, Fig. $5 \mathrm{E}$ ), $\bar{h}_{k}$ indicated rapid erosion and deposition (up to $1 \mathrm{~m}$ ) that was not observed with the altimeters (Fig. 5A). Relative to the other altimeter locations, RMSE was smallest at the outer altimeter $(0.39 \mathrm{~m})$ where $\bar{h}_{k}$ explained $64 \%$ of the observed variance (Table 3 ). Video images of breaking waves in the surf zone (Fig. 5E) suggest the surfzone sandbar moved offshore $\sim 100 \mathrm{~m}$ between Mar and mid-Apr, and then moved $\sim 50 \mathrm{~m}$ onshore between Apr and Sep (black curve, Fig. 5E), consistent with the accretion until mid-Apr and the erosion from Apr through Sep observed in the outer-surf zone (Fig. 5A).

At the middle altimeter, seafloor elevation changes occurred more frequently from Oct through early Mar (Fig. 5B). The patterns of erosion and accretion at the middle altimeter are consistent with the changing location of the sandbar (compare the black curve with the dotted red lines in Fig. 5E). For example, the maxima (minima) in seafloor elevation estimated from the altimeter typically occur when $x_{\text {break }}$ is near (far from)

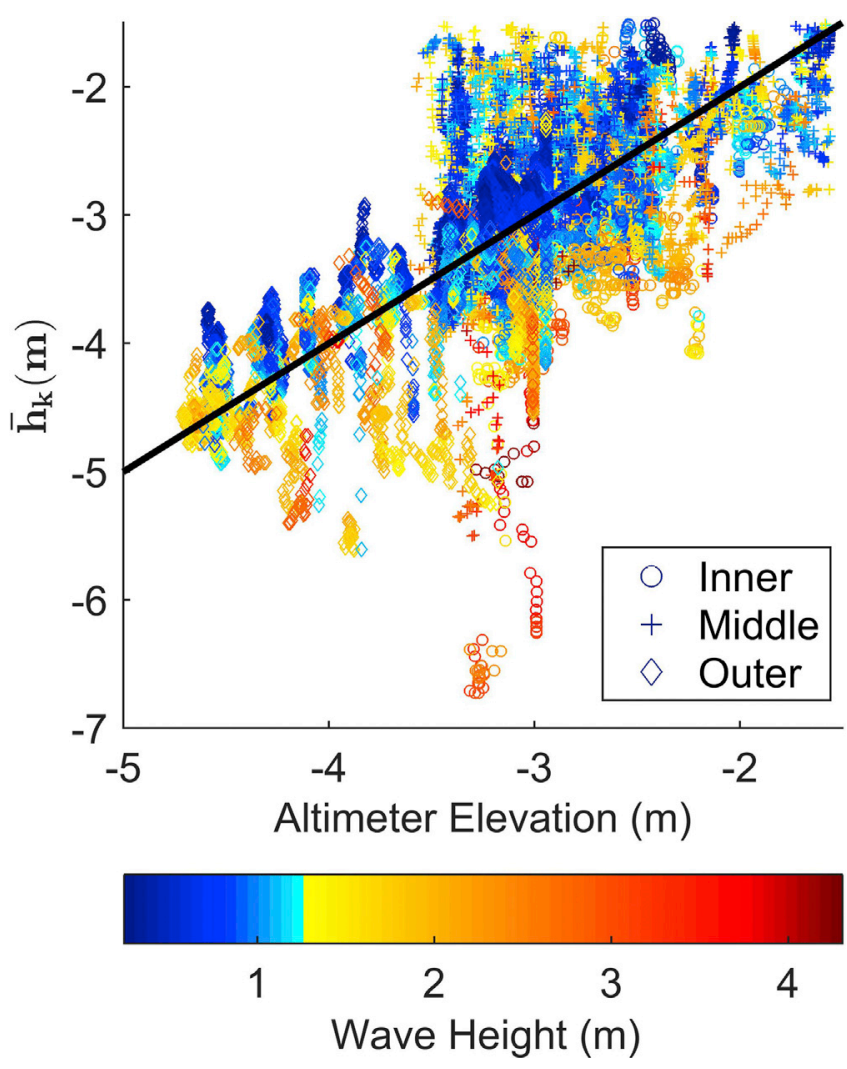

Fig. 6. cBathy Kalman filtered bathymetry $\left(\bar{h}_{k}\right)$ versus altimeter bathymetry for the inner (circles), middle (cross-hair), and outer (diamond) altimeters colored by wave height, $H_{s}$ (scale on bottom). The solid black line represents the 1:1 line. (For interpretation of the references to color in this figure legend, the reader is referred to the Web version of this article.)

the middle altimeter [i.e., when the black curve in Fig. 5E is near (far from) the center dotted red line]. It is unclear if the sometimes rapid accretion and erosion at the middle altimeter, were caused by migrating large bedforms or by rapid sandbar position changes. For example, in early Oct and early Feb, the altimeter indicated $1.2 \mathrm{~m}$ of erosion in 4 days, and in early Jan, the altimeter observed $1.0 \mathrm{~m}$ of accretion in $12 \mathrm{~h}$ (not visible at the scale shown in Fig. 5E). Similar to the outer altimeter, there are significant differences (as much as $2 \mathrm{~m}$, compare blue with red curve in Fig. 5B) between the middle altimeter and $\bar{h}_{k}$, particularly during storms (black curve in 5D). The video-derived depths $\bar{h}_{k}$ and altimeter elevations agreed best during the calm summer months May through Aug. However, $\bar{h}_{k}$ were $0.5-1.0 \mathrm{~m}$ shallower than the middle altimeter observations during late Oct, Dec, and from mid-Feb through Apr, when the altimeter was located just onshore of the sandbar (compare middle dotted red line with the black curve, Fig. 5E). Over the whole year, RMSE and bias were 0.52 and $0.22 \mathrm{~m}$, respectively (Table 3 ).

The seafloor elevation estimated at the inner altimeter (located between the shoreline and the surfzone sandbar for all 11 months, Fig. 5E) had the lowest standard deviation over the year relative to the other gauge locations (Fig. 5C, Table 3). Similar to other locations, the seafloor elevation changes were more frequent between Sep and mid-Apr, and sometimes evolution was rapid. For example, on 05 Jan during the start of a storm, the altimeter indicated $0.8 \mathrm{~m}$ of erosion in $6 \mathrm{~h}$, followed immediately by $1 \mathrm{~m}$ of accretion in $3 \mathrm{~h}$ (not visible at the resolution of Fig. 5). At the inner altimeter, $\bar{h}_{k}$ were often biased deep by $0.5 \mathrm{~m}$ from mid-Mar through the end of Sep. Over the whole year, RMSE and bias were 0.49 and $-0.33 \mathrm{~m}$, respectively (Table 3 ).

The continuous observations of seafloor elevation from the three altimeters provide a unique data set to evaluate video-based cBathy's performance in a wide range of environmental conditions. Overall, 

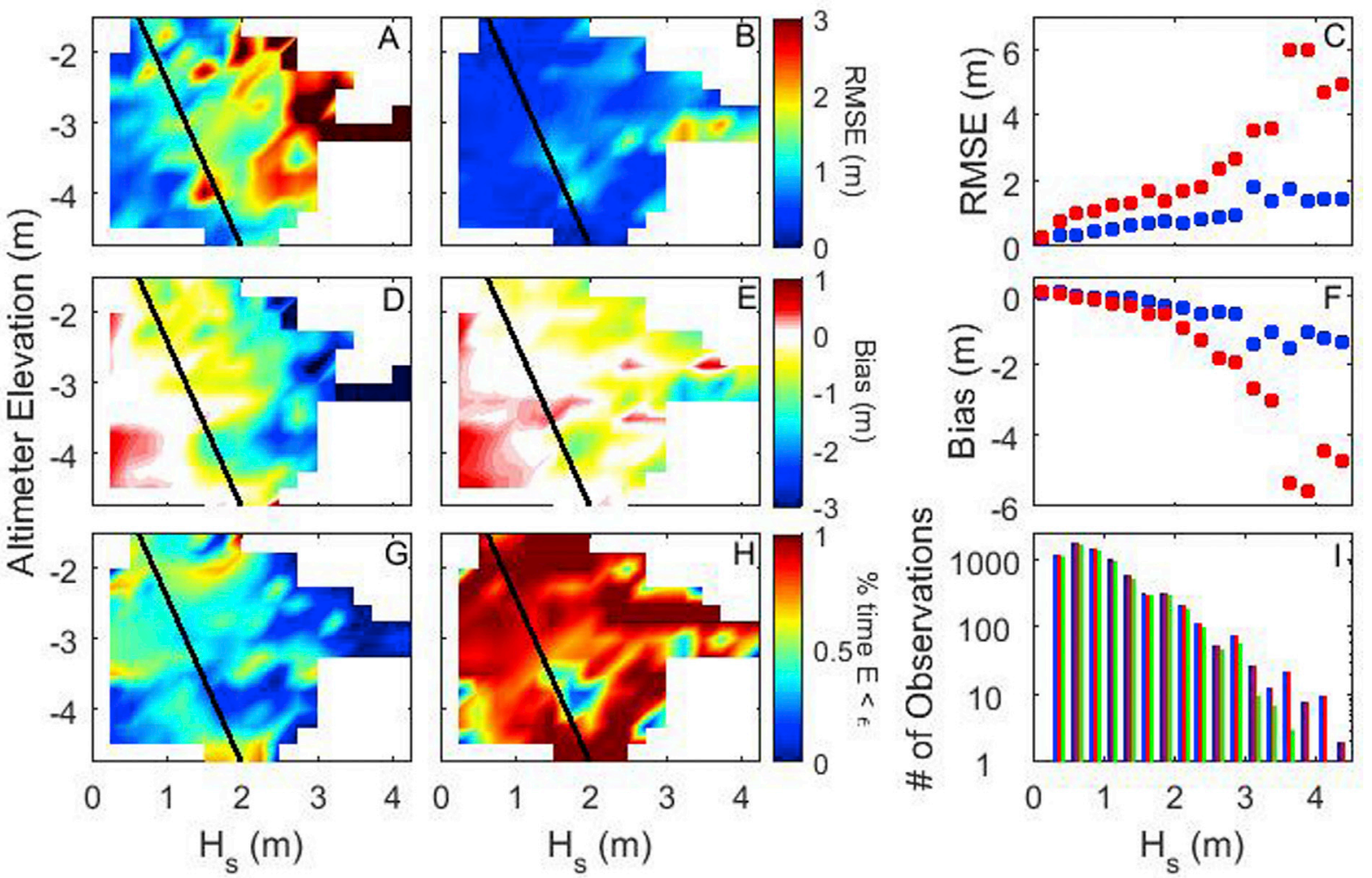

Fig. 7. The RMSE and bias between (A, D) cBathy $\widehat{h}_{k}$ and altimeter bathymetry and (B, E) cBathy Kalman-filtered $\bar{h}_{k}$ and altimeter bathymetry as a function of altimeter seafloor elevation and wave height, $H_{s}$ (color scales at right). (C) RMSE and (F) bias versus $H_{s}$ for cBathy $\widehat{h}_{k}$ (red circles) and cBathy $\bar{h}_{k}$ (blue circles) calculated over all depths for each wave height bin. The percentage of time (divided by 100) observed errors, $E_{P 2}$ and $E_{P 3}$, were smaller than cBathy confidence intervals, $\varepsilon_{\mathrm{P} 2}$ and $\varepsilon_{\mathrm{P} 3}$, as a function of altimeter seafloor elevation and wave height, $H_{s}$ for (G) cBathy $\widehat{h}_{k}$ and $(\mathrm{H})$ cBathy $\bar{h}_{k}$ (color scale at right). The black line in A-H represents $H_{s} / h=0.42$. The number of observations in each wave height bin are shown in (I) for the inner (blue), middle (red), and outer (green) altimeters. (For interpretation of the references to color in this figure legend, the reader is referred to the Web version of this article.)
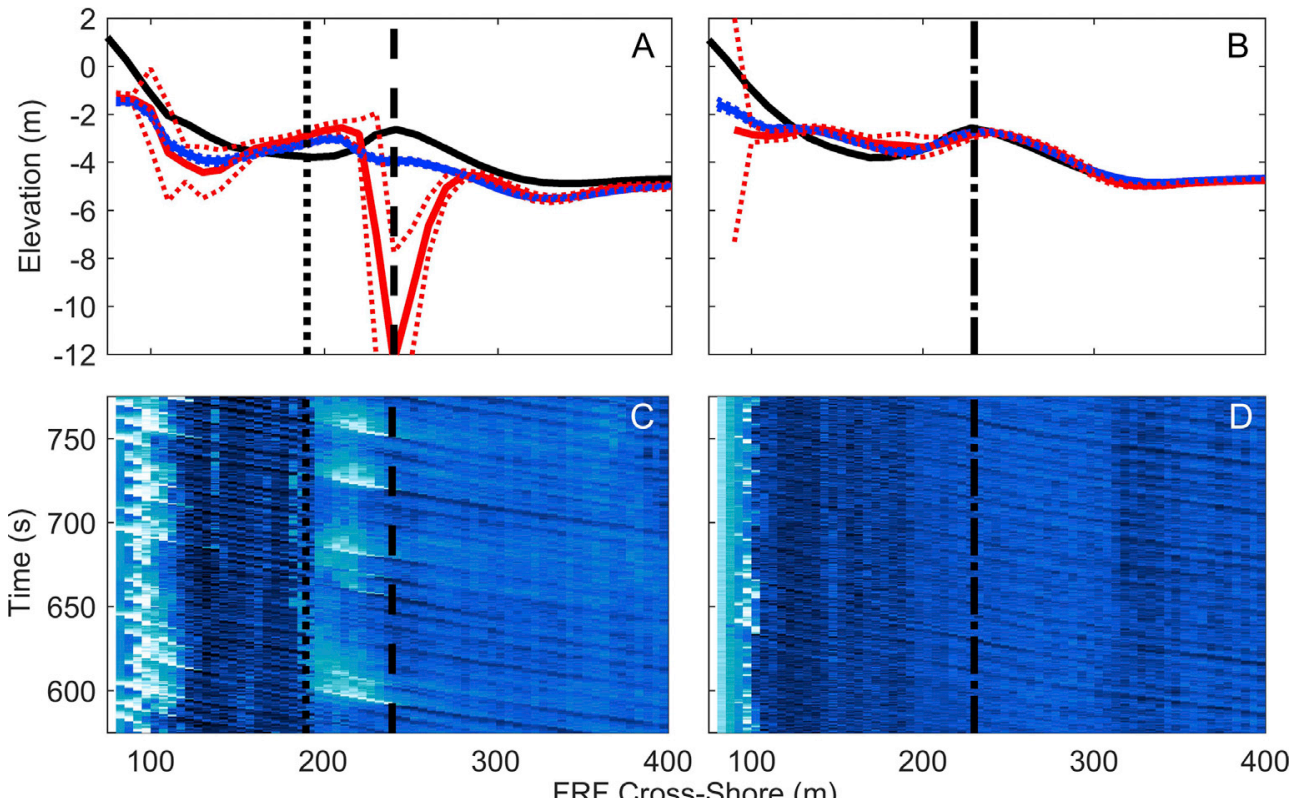

Fig. 8. Seafloor elevation (alongshore $=715 \mathrm{~m}$ ) versus cross-shore location on (A) 08 and (B) 23 Oct, 2015 estimated with surveys (solid black curves), cBathy (solid red curves), and Kalman filtered cBathy (solid blue curves). The range of cBathy estimated errors $\varepsilon_{P 2}$ are shown by the dotted red curves, and $\varepsilon_{P 3}$ are shown by the blue dotted curves. Pixel intensities (white is wave breaking) on (C) 08 and (D) 23 Oct, 2015 as a function of time and cross-shore position near the alongshore position of the altimeters. The vertical dotted black lines are the cBathy estimates of the sandbar crest locations, and the vertical dashed black lines are the survey estimates of the sandbar crest location. (For interpretation of the references to color in this figure legend, the reader is referred to the Web version of this article.) standard deviations $\left(\sigma_{Z}\right)$ and range $\left(Z_{\text {range, }}\right.$, calculated as the difference between the maximum and minimum seafloor elevation observed over the whole time series) in $\bar{h}_{k}$, were larger than the altimeter observations (Table 3). The standard deviation $\sigma_{Z}$ estimated from altimeters and
cBathy decreased from offshore to onshore $(0.6-0.3 \mathrm{~m}$ and 0.7 to $0.5 \mathrm{~m}$, respectively) (Table 3). Combining the data from all three altimeters into one data set allows a synthesis of performance of $\bar{h}_{k}$ over a range of water depths $(-4.8 \mathrm{~m}<h<-1.5 \mathrm{~m})$ and wave conditions (Fig. 6). RMSE and 
bias for the combined data set were 0.50 and $0.04 \mathrm{~m}$, respectively, and $\bar{h}_{k}$ explained $50 \%$ of the variance in the observed altimeter seafloor elevations (Table 3, Fig. 6). Similar to the survey data, during low waves $\left(H_{s}<1.2 \mathrm{~m}\right.$, blue symbols Fig. 6$), \bar{h}_{k}$ and the altimeters compare well with each other. However when $H_{s}>1.2 \mathrm{~m}$, there is significantly more scatter (departure of warm colored symbols from the black 1:1 line, Fig. 6). The largest scatter occurred when $-3.5<h<-3.0 \mathrm{~m}$ with -6.8 $<\bar{h}_{k}<-1.5 \mathrm{~m}$. The largest negative depth errors were observed at the inner altimeter (circles, Fig. 6) when $H_{s}>2.5 \mathrm{~m}$, whereas the largest positive depth errors were observed at the middle altimeter (crosses, Fig. 6) when $\sim 1.2<H_{s}<\sim 2 \mathrm{~m}$. In the following section, video-based cBathy depth errors will be quantified relative to depth and wave height, and causes of the scatter in cBathy bathymetry estimates, including effects of the Kalman filter, also will be discussed.

\section{Discussion}

\subsection{Video-based cBathy accuracy assessment}

Video-based cBathy errors have been related to both depth and wave height (Holman et al., 2013; Holland, 2001), although previous analyses have not included conditions where $H_{s}>2 \mathrm{~m}$. To investigate errors over a wider range of conditions, the data were organized into seafloor elevation $(h)$ and wave height $H_{s}$ bins ( $0.25 \mathrm{~m}$ resolution), and performance statistics (RMSE \& bias) for both $\widehat{h}_{k}$ and $\bar{h}_{k}$ were analyzed for all observed $h-H_{s}$ combinations (Fig. 7).

At all depths and wave heights, RMSEs for $\widehat{h}_{k}$ were larger than those for $\bar{h}_{k}$ (compare the color contours in Fig. 7A with those in Fig. 7B, and the blue circles with the red circles in Fig. $7 \mathrm{C}$ ), illustrating the utility of the Kalman filter in moderating error in the depth inversion. During low waves $\left(H_{s}<1.2 \mathrm{~m}\right)$ which are unlikely to be breaking $\left(H_{s} / h<0.42\right)$, RMSE was smallest $(0<$ RMSE $<1 \mathrm{~m})$ across all depths for both $\widehat{h}_{k}$ and $\bar{h}_{k}$ (blue colors below the black line, Fig. 7A and B; where the black line indicates $H_{s} / h=0.42$ ), consistent with (Holman et al., 2013). When $H_{s}>1.2 \mathrm{~m}$, the RMSE for $\widehat{h}_{k}$ increased with $H_{s}$ for all depths, and was particularly large (RMSE $>3 \mathrm{~m}$ ) when $H_{s} / h>0.42$ and waves likely were breaking at or offshore of that depth (dark red colors above the black line, Fig. 7A). Localized peaks in RMSE for $\widehat{h}_{k}$ also occurred at $h \approx-2$ and $-4 \mathrm{~m}$, when $1.2<H_{s}<2 \mathrm{~m}$. For $\bar{h}_{k}, 1.0<$ RMSE $<1.5 \mathrm{~m}$ when $1.2<$ $H_{s}<2 \mathrm{~m}$ and $-4<h<-3 \mathrm{~m}$ or $h \approx-2 \mathrm{~m}$ (light blue colors, Fig. 7B), and RMSE $>1.5 \mathrm{~m}$ when $H_{s}>2 \mathrm{~m}$ and $h \approx-3 \mathrm{~m}$ (yellow and orange colors, Fig. 7B).

Biases for $\widehat{h}_{k}$ and $\bar{h}_{k}$ had similar trends with wave height and water depth (Fig. 7D and E). Slight positive biases $(0<$ bias $<0.5 \mathrm{~m})$ occurred when $H_{s}<1 \mathrm{~m}$ and $H_{s} / h<0.42$, and a trend towards negative biases occurred with increasing wave height and decreasing depths (cool colors above the black line in Fig. 7D and E). Negative biases were larger for $\widehat{h}_{k}$ than for $\bar{h}_{k}$, particularly when $H_{s}>2 \mathrm{~m}$ (compare cool colors in Fig. 7D with those in Fig. 7E, and red with blue circles in Fig. 7F). When $1.2<$ $H_{s}<2 \mathrm{~m}$ and $-4<h<-3 \mathrm{~m}$, where there were localized peaks in RMSE (Fig. 7A and B), biases in $\bar{h}_{k}$ were either positive or negative, with the negative biases occurring at slightly deeper depths.

Combining data from all water depths allows extension of Fig. 6 from (Holman et al., 2013) to higher wave heights $\left(2<H_{s}<4 \mathrm{~m}\right.$ ) (Fig. 7C, F). Both RMSE and bias for $\bar{h}_{k}$ followed similar trends to (Holman et al., 2013), maintaining a similar, linear slope through the higher wave heights. The $\widehat{h}_{k}$ results (not shown in (Holman et al., 2013)) are of interest when using cBathy from data collected from unmanned aerial systems (UAS) (Holman et al., 2017) where continuous sampling over hours to days may not be possible, and thus cBathy analysis may be restricted to $\widehat{h}_{k}$ results. Although the RMSE in $\widehat{h}_{k}$ maintained a linear slope with increasing $H_{s}$, bias in $\widehat{h}_{k}$ increases more rapidly when $H_{s}>2 \mathrm{~m}$ then when $H_{s}<2 \mathrm{~m}$ (red circles, Fig. 7F).

The performance of cBathy confidence intervals also was assessed by evaluating how often the observed errors, $E_{P 2}$ and $E_{P 3}$ were less than the predicted errors, $\varepsilon_{\mathrm{P} 2}$ and $\varepsilon_{\mathrm{P} 3}$ for each wave height-water depth bin (Fig. $7 \mathrm{G}$ and $\mathrm{H}$, respectively). Following the suggestion of (Holman et al., 2013), $\varepsilon_{\mathrm{P} 3}$ were multiplied by 7 for this analysis. The error $\varepsilon_{\mathrm{P} 2}$ did not bound the errors at a 95\% confidence interval level for any water depth-wave height combination (no deep red colors, Fig. 7G), suggesting $\varepsilon_{\mathrm{P} 2}$ were not well calibrated. When multiplied by $7, \varepsilon_{\mathrm{P} 3}$ bounded the errors at least $75 \%$ of the time across most of the domain (deep red contours in Fig. 7H), except when $1<H_{s}<2 \mathrm{~m}$ and $-4<h<-3 \mathrm{~m}$. When not multiplied by 7 , results for $\varepsilon_{\mathrm{P} 3}$ were similar to $\varepsilon_{\mathrm{P} 2}$, and did not bound the errors more than $50 \%$ of the time for any $\left(H_{s}, h\right)$ bin. Correct calibration of video-based cBathy confidence intervals will be important as cBathy results are assimilated into numerical models (Wilson et al., 2010, 2014) or used operationally to quantify coastal change.

\subsection{Sandbar position estimates}

Although the sandbar position in $\bar{h}_{k}$ is similar to the surveyed bathymetry for relatively small waves (Fig. 4C), the sandbar in $\bar{h}_{k}$ was biased onshore relative to surveyed sandbar positions during larger wave conditions (Fig. 4F). On 08 October $\left(H_{s}=1.2 \mathrm{~m}, \gamma_{\text {off }}=0.51\right)$ both $\widehat{h}_{k}$ (red curve in Fig. 8A) and $\bar{h}_{k}$ (blue curve in Fig. 8A) agreed well with surveyed bathymetry (solid black curve in Fig. 8A) offshore of the region of wave breaking ( $x>300 \mathrm{~m}$ in Fig. $8 \mathrm{~A}$ and $\mathrm{B}$ ), where the linear dispersion relationship is accurate to within 20\% (Thornton and Guza, 1982). However, $\widehat{h}_{k}$ and $\bar{h}_{k}$ diverged from the surveyed bathymetry onshore of $\mathrm{x}=300 \mathrm{~m}$, especially near the sandbar crest (dashed black vertical lines in Fig. 8), where a deep trough exists in $\bar{h}_{k}$. The largest errors in $\widehat{h}_{k}$ relative to the survey occurred at the initiation of wave breaking (white regions in Fig. $8 \mathrm{C}$ are from breaking waves), similar to previous results (Holman et al., 2013). Although the $\bar{h}_{k}$ estimate of uncertainty was large over the sandbar crest (dotted red curves in Fig. 8A), it was less than the observed error (i.e., $\varepsilon_{P 2} \quad E_{P 2}$ ). Near the onshore edge of the breaking region, $\bar{h}_{k}$ was shallower than the surveyed seafloor elevation in the

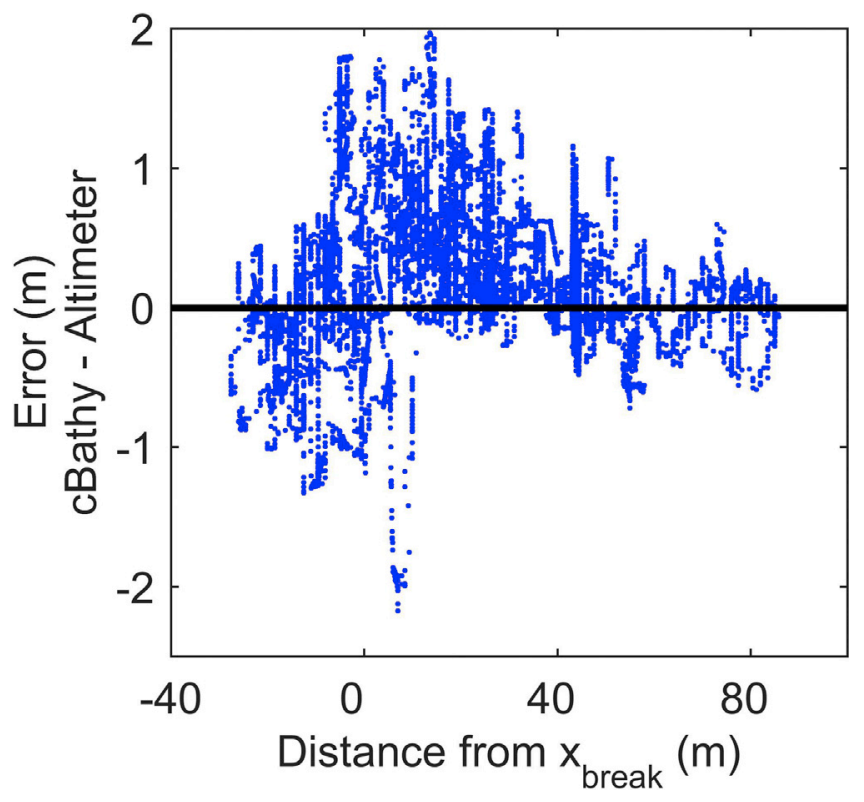

Fig. 9. Difference between cBathy and altimeter estimates of seafloor elevation versus distance of the estimate from the location of peak wave breaking. Positive (negative) distances are offshore (onshore) of the peak in wave breaking, and positive (negative) errors indicate cBathy underestimated (overestimated) depth relative to the altimeter. 

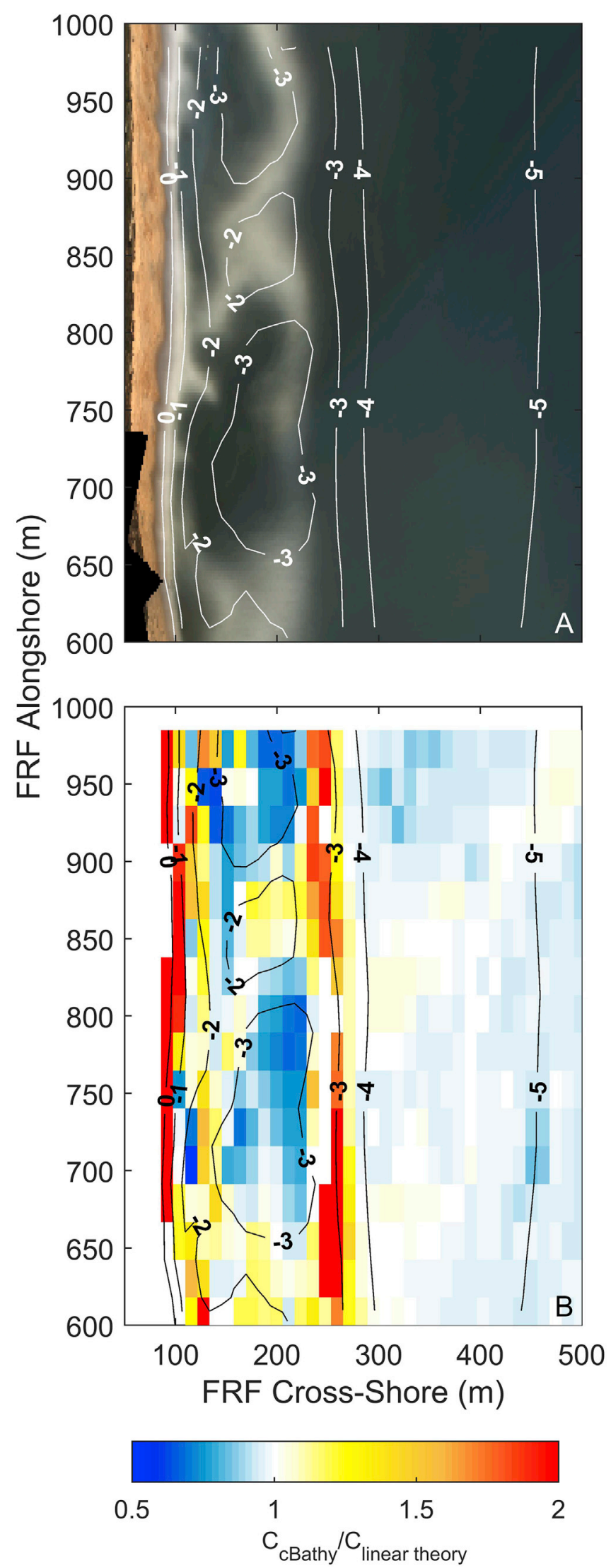

(caption on next column)
Fig. 10. (A) Argus video time-average imagery rectified into the FRF local coordinate system and (B) the ratio of cBathy-estimated wave speed to linear theory (color scale at bottom) as a function of position for 08 Oct 2015. 1-m elevation contour intervals of the corresponding gridded bathymetric survey are overlain in white (A) and black (B). (For interpretation of the references to color in this figure legend, the reader is referred to the Web version of this article.)

trough between the sandbar and the shoreline (Fig. 8A, $\mathrm{x} \sim 200 \mathrm{~m}$ ). Similar to near the sandbar crest, the video-based cBathy estimate of uncertainty was less than the observed error $\left(\varepsilon_{P 2} E_{P 2}\right)$. The combination of the deep anomaly over the crest and the shallow anomaly over the trough resulted in an onshore bias in sandbar location in $\widehat{h}_{k}$. Onshore of $\mathrm{x}=150 \mathrm{~m}$, where waves broke at the shoreline (white regions in Fig. $8 \mathrm{C}$ ), $\widehat{h}_{k}$ estimates were deeper than surveyed bathymetry.

The Kalman filtered estimates of bathymetry, $\bar{h}_{k}$, (blue curves in Fig. 8) were smoothed in time relative to the unfiltered $\widehat{h}_{k}$ (red curves in Fig. 8), with the degree of smoothing dependent on measurement error, $\varepsilon_{P 2}$, and process noise variance, $Q$ (Holman et al., 2013). On 08 Oct, $\varepsilon_{P 2}$ near the surveyed bar crest was large, and thus reduced the influence of $\widehat{h}_{k}$ (i.e., reducing $K$ ). In contrast, onshore of the sandbar, the Kalman filter weighed the shallow anomaly in $\widehat{h}_{k}$ more heavily because $\varepsilon_{P 2}$ was small. The errors in $\widehat{h}_{k}$ and $\varepsilon_{P 2}$ combined to result in the apparent 30-m onshore shift of the sandbar in $\bar{h}_{k}$ (Figs. 4F and 8A, Table 3).

In contrast, on 23 Oct $\left(H_{s}=0.75 \mathrm{~m}, \gamma_{\text {off }}=0.32\right)$ waves broke only at the shoreline (Fig. 8D), and the video-based cBathy sandbar position agrees well with the surveyed sandbar position (Fig. 8B). Accordingly, the bias between the surveyed and the cBathy estimates $\left(\widehat{h}_{k}\right.$ and $\left.\bar{h}_{k}\right)$ in sandbar position was small on all days with minimal wave breaking over the sandbar $\left(\gamma_{\text {off }}<0.35\right)$.

The opposing depth biases apparent at the initiation and termination of wave breaking relative to the survey data also were apparent relative to the altimeter data. For example, the errors between $\bar{h}_{k}$ and altimeter estimates of seafloor elevation at the middle altimeter depended on its location relative to $x_{\text {break }}$ (i.e., relative to its location in the surfzone) (Fig. 9). When the altimeter was located nearby, but offshore of $x_{b r e a k}$ (offshore or outer surfzone, negative abscissa values in Fig. 9), $\bar{h}_{k}$ was too deep relative to the altimeter-estimated seafloor elevation (negative ordinate values in Fig. 9). When the altimeter was located nearby (within $\sim 30 \mathrm{~m}$ ), but onshore of $x_{\text {break }}, \bar{h}_{k}$ was too shallow relative to the altimeter-estimated seafloor elevation (positive ordinate values in Fig. 9). When the altimeter was more than $\sim 40 \mathrm{~m}$ onshore of $x_{\text {break }}$, the errors were evenly distributed $\pm 0.50 \mathrm{~m}$. The sign of these errors is consistent with the sign of the errors between the video-derived and surveyed bathymetry, with $\bar{h}_{k}$ too deep near the initiation of wave breaking and too shallow where wave breaking ceases (often in the trough between sandbar and shoreline). These negative and positive biases near the sandbar when waves were breaking may also explain the high RMSE and alternating negative and positive biases observed when $1<H_{s}<2 \mathrm{~m}$ and $-4<h<-2 \mathrm{~m}$ in Fig. 7E (see section 4.1).

\subsection{Sources of errors}

\subsubsection{Errors in $\widehat{h}_{k}$}

Errors in $\widehat{h}_{k}$ can be caused by deviations in wave speeds from the linear dispersion relationship and by errors in how wave speeds are estimated from the video imagery. To evaluate the speed estimates, weighted averages of the wave speeds calculated for the four video-based $f-k$ pairs determined in step 1 (using the weights from step 2) were compared with weighted-average speeds using the same frequencies and weights, but with wavenumbers calculated with linear theory and the observed depths from the altimeter data (not shown) and from each survey (example from 08 Oct shown in Fig. 10). On 08 Oct $\left(\mathrm{H}_{\mathrm{s}}=1.2 \mathrm{~m}\right.$ ) waves broke on the sandbar (Fig. 10A), and the wave speed estimated 

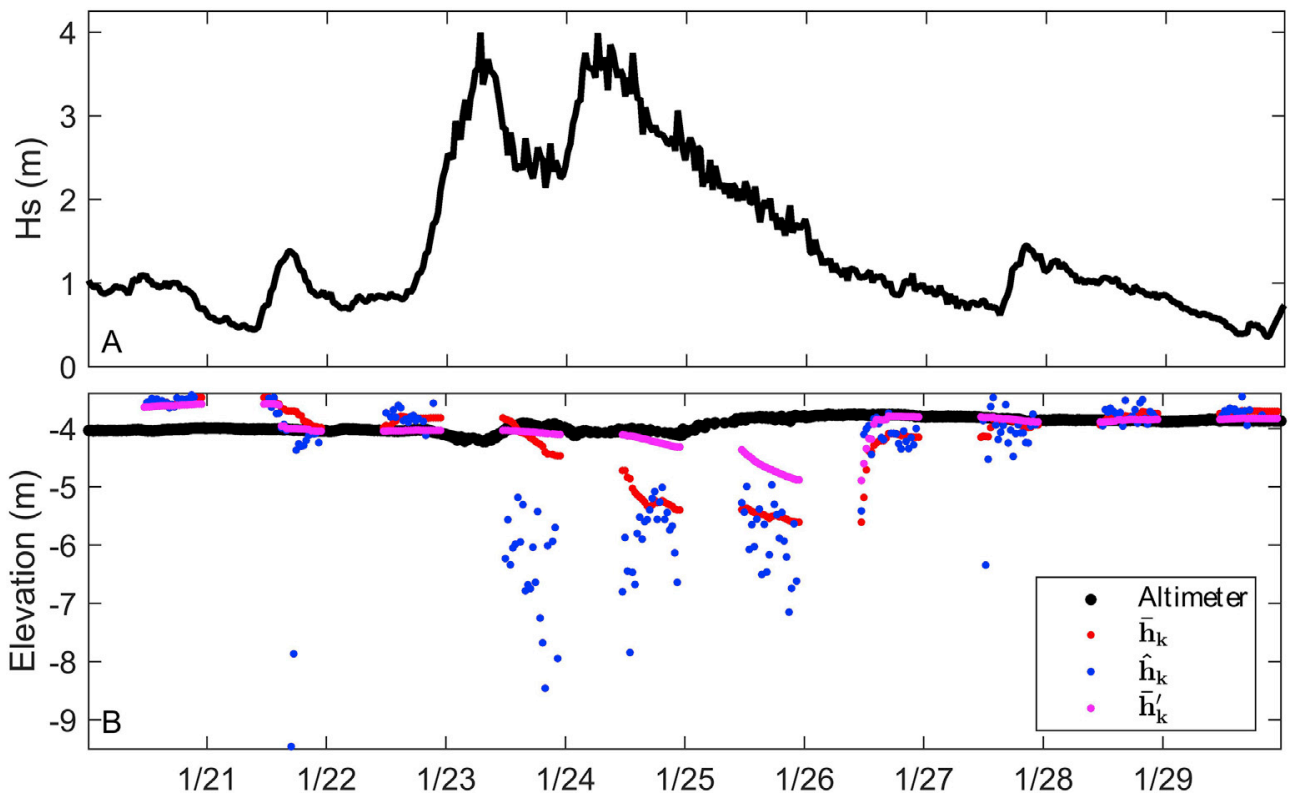

Fig. 11. (A) Significant wave height and (B) outer surfzone seafloor elevations measured with an altimeter (black circles), and estimated with Kalman-filtered cBathy (red circles, $\bar{h}_{k}$ ), half-hour unfiltered cBathy (blue circles, $\widehat{h}_{k}$ ), and updated Kalmanfiltered cBathy (magenta circles, $\bar{h}_{k}{ }^{\prime}$ ) versus date in Jan 2016. (For interpretation of the references to color in this figure legend, the reader is referred to the Web version of this article.) from video-based cBathy was 1.2-2.2 times higher than linear wave theory at the onset of wave breaking on the offshore edge of the sandbar (warm colors near cross-shore $=275 \mathrm{~m}$ in Fig. 10B), and 0.6 to 0.8 times lower than linear theory in the trough between the sandbar and the shoreline near the termination of breaking (cool colors for $150<$ crossshore $<250 \mathrm{~m}$ in Fig. 10B). The sign of the deviations in wave speeds from linear wave theory are consistent with the onshore shift in the location of the video-based cBathy sandbar (Fig. 8A), and with previous laboratory and field studies (Catálan and Haller, 2008; Guza and Thornton, 1980; Thornton and Guza, 1982; Elgar and Guza, 1985a, 1985b; Okamoto et al., 2010; Inman et al., 1971; Svendsen et al., 2003; Tissier et al., 2011; Postacchini and Brocchini, 2014). Over the year-long altimeter data set, video-derived wave speeds were up to 3 times linear theory values during storms (not shown). The magnitudes of the deviations in breaking wave speeds from linear theory at the onset of wave breaking (1.2-3 times linear theory) are larger than in prior observations of wave speeds for waves breaking over sandbars in the field (1.2-1.4 times linear theory (Holland, 2001; Thornton and Guza, 1982; Inman et al., 1971; Suhayda and Pettigrew, 1977; Tissier et al., 2011)).

The relatively high video-derived wave speeds at the initiation of wave breaking may be a result of errors related to incorrect estimates of $f$ or $k$ from imagery, possibly owing to a shift in the transfer function relating the optical signature of waves to the true waveform (Stockdon and Holman, 2000). Offshore of the breakpoint, the imaged seaward face of the wave tends to be light, whereas the imaged landward face of the wave tends to be dark. During wave breaking and the initiation of the wave roller, the landward face of the wave becomes bright (white foam) and the seaward face becomes darker (e.g., Fig. 8C). At the onset of wave breaking, the transition in the transfer function could lead to a jump in wave phase (an apparent acceleration), whereas at the end of wave breaking the second transition in the transfer function may cause an apparent deceleration (Stockdon and Holman, 2000). The corresponding errors in wave speed are consistent with the video-derived depth errors observed here. More data and analyses are needed to determine whether video-derived wave speeds near the sandbar reflect true accelerations and decelerations in the speed of breaking waves or whether they are an artifact of the transition in the optical transfer function (or some combination of both). Nevertheless, this analysis suggests that although video-based cBathy bathymetry can be used to quantify sandbar morphology during low non-breaking waves, caution should be used as wave heights increase and waves break over the sandbar. It is important to note, that depending upon the source of these errors (linear wave theory vs. the optical transfer function), radar-derived $\widehat{h}_{k}$ may not have similar cautions, as radar-based cBathy exploits a different transfer function, avoiding problems associated with the optical signature of wave breaking.

\subsubsection{Errors in $\bar{h}_{k}$}

Errors in $\bar{h}_{k}$ can be caused by incorrect assumptions in the Kalman filter and by incorrect estimates of $\widehat{h}_{k}$ and $\varepsilon_{P 2}$. The Kalman filter in the cBathy algorithm is used to increase the quality of the final bathymetry estimates, $\bar{h}_{k}$, by more strongly weighing high quality $\widehat{h}_{k}$, and minimizing the effects of low quality $\widehat{h}_{k}$, such as may occur at the onset of wave breaking or during fog or storms (Holman et al., 2013). However, depth biases of 1-2 $\mathrm{m}$ across the surfzone still occur in $\bar{h}_{k}$ during many storms [Fig. 5, compare blue with red curves in panels A, B, and C].

The altimeter data enable evaluation of the effectiveness of the Kalman filter at reducing large errors in $\widehat{h}_{k}$ during storms. The Kalman filter in cBathy requires a site-specific process error, $Q$, and the measurement error, $R$, which, if estimated poorly, may be a source of error in the final $\bar{h}_{k}$ estimate. For example, $\varepsilon_{P 2}$, which are used to calculate $R$, are not calibrated with $E_{P 2}$, particularly at high wave heights (Fig. 7G). To assess the performance of the Kalman filter independent of errors in $\varepsilon_{P 2}$ or $Q$, the altimeter seafloor elevations during a storm in January $\left(0.4<H_{s}<4.0 \mathrm{~m}\right)$ can be used to define the true measurement error, $R=R_{o b s}=E_{P 2}^{2}$, and the true process noise variance as

$Q \Delta t=\Delta Z^{2}=\left(Z_{t}-Z_{t-1}\right)^{2}$,

where $Z$ is the seabed elevation measured by the outer-surf zone altimeter at sequential cBathy solution times $(t-1, t)$, and using (2) and (3) estimate the Kalman gain as

$K=K^{\prime}=\frac{P_{k-1}+\Delta Z^{2}}{P_{k-1}+\Delta Z^{2}+R_{o b s}}$.

Substituting (6) for K in (1) to solve for updated Kalman-filtered bathymetry, $h_{k}^{\prime}$, results in improved bathymetry estimates at the outer surfzone altimeter on 23-24 Jan (Fig. 11B, compare magenta curve with red and blue curves). However, even with accurate inputs of $Q$ and $R, h_{k}^{\prime}$ is still biased deep by $1 \mathrm{~m}$ at the end of $25 \mathrm{Jan}$. These incorrect estimates occurred because the seafloor accreted $0.25 \mathrm{~m}$ overnight from 24 to 25 
Jan (black curve, Fig. 11B), which caused an increase in $\Delta Z^{2}$ and in the resultant process error (not shown). The unsigned increase in process error decreased confidence in the prior estimate of $h_{k}^{\prime}$, and therefore more weight was placed on the biased estimate of $\widehat{h}_{k}$, even though $R_{o b s}$ was large. Assimilation of the biased estimate of $\widehat{h}_{k}$ caused apparent erosion, because $\widehat{h}_{k}$ were too deep, even though the observed elevation changes in $\Delta Z^{2}$ were accretionary. $h_{k}^{\prime}$ became more accurate on the morning of 26 Jan when $\widehat{h}_{k}$ were accurate and $R_{o b s}$ decreased (compare blue dots with the black curve in Fig. 11B). The largest deviation between both $\bar{h}_{k}$ and $h_{k}^{\prime}$ and the altimeter occurs after the peak of the storm, due to lag induced by the Kalman filter.

Improving measurement and process variance estimates improved the Kalman-filtered results, until erroneous values of $\widehat{h}_{k}$ overwhelmed the filter (compare magenta and red curves with the black curve in Fig. 11B). Both $\bar{h}_{k}$ and $h_{k}^{\prime}$ tended towards the erroneously deep $\widehat{h}_{k}$ with increasing time and error variances because the Kalman filter is not designed to account for systematically biased errors that occur on the time-scale as real bathymetric change. Correctly accounting for real bathymetric change is problematic both because 1) $Q$ must be redefined for each new location where cBathy is used, and 2) the scale of real bathymetric change is of similar magnitude to the errors in cBathy. Process error is difficult to quantify even when data are available to establish an empirical relationship. For example, there were no statistically significant relationships between the process error defined for Duck by (Holman et al., 2013) and the true bathymetric change at each altimeter over the year-long data set (not shown).

To improve bathymetry estimates during storms, future work should focus on improving the quality of $\widehat{h}_{k}$ during large waves, reducing the effects of biased estimates of $\widehat{h}_{k}$ on the Kalman filter, and developing advanced approaches to utilize numerical models to estimate bathymetry (Wilson et al., 2010, 2014). The results here suggest that video-based cBathy bathymetry may not provide reliable estimates of surfzone morphology change during storms. The results also suggest that with improved quality control of biased $\widehat{h}_{k}$ during breaking waves, video-based cBathy may provide reliable estimates of seasonal bathymetric change, particularly offshore of the sandbar. For example, if $\bar{h}_{k}$ estimates when $H_{s}>1.2 \mathrm{~m}$ are removed from the analysis (27\% of the sample time period), $\bar{h}_{k}$ explains $83 \%$ of the variability in seafloor elevation changes at the outer altimeter over the year-long sample period. This wave height threshold, which identifies when waves break over the sandbar, could be translated to other sites by converting to $\gamma_{\text {off }}$ utilizing an estimate of the sandbar crest depth. For example, dividing the offshore wave height threshold, $H_{s}=1.2$, by the average sandbar crest elevation for this study site, $\bar{z}_{S B}=2.4 \mathrm{~m}$, yields a threshold $\gamma_{\text {off }}=0.50$. This $\gamma_{\text {off }}$ threshold could be used with a rough estimate of the sandbar crest depth $z_{S B}$ to estimate a maximum operational wave height $\left(\gamma_{o f f} * h_{c}\right)$ for video-based cBathy at other locations. Alternatively, analysis of the video timex images also may be sufficient to identify when waves are breaking over the bar.

\section{Conclusions}

Surfzone bathymetry estimated with a video-based linear depth inversion algorithm, cBathy, was compared with bathymetry estimated with vessel-based hydrographic surveys and with in-situ altimeters for a wide range of wave conditions. Surfzone seafloor elevation trends estimated with cBathy are qualitatively similar to those observed over one year with in-situ altimeters. When wave heights were less than $1.2 \mathrm{~m}$, $R M S E<0.5 \mathrm{~m}$ and $-0.5<$ bias $<0.5 \mathrm{~m}$ in water depths between 1.5 and $4.5 \mathrm{~m}$, similar to previous results. During these conditions, cBathy explained $83 \%$ of the variance observed in seafloor elevation changes offshore of the sandbar over a 1-year time period. However, during storms when wave heights exceeded $3 \mathrm{~m}$, video-derived bathymetry was biased deep relative to the altimeters with $3<R M S E<6 \mathrm{~m}$ in unfiltered results and $1.5<$ RMSE $<2 \mathrm{~m}$ for Kalman filtered results. Although the Kalman filter improved the performance of video-based cBathy, the filter could not maintain robust bathymetry estimates during storms. In addition, during calmer conditions, when waves broke over the sandbar, video-based cBathy overestimated water depths by up to $2 \mathrm{~m}$ over the offshore edge of the sandbar, and underestimated depths in the deeper trough between the sandbar and the shoreline, where waves ceased breaking. As a result, the cross-shore location of the sandbar was biased onshore by $18-40 \mathrm{~m}$ when wave heights exceeded $1.2 \mathrm{~m}$ and broke over the bar (offshore wave height divided by bar crest depth $\gamma_{\text {off }}>0.5$ ). The onshore bias was 3-4 $\mathrm{m}$ when wave heights were less than $0.8 \mathrm{~m}$ and did not break over the sandbar $\left(\gamma_{o f f}<0.35\right)$. The onshore bias was caused by over prediction (up to $300 \%$ faster than linear theory) of video-based wave speeds at the initiation of wave breaking and under prediction (as much as $60 \%$ slower than linear theory) of wave speeds at the termination of wave breaking. The difference from linear theory may be owing to nonlinear effects on the dispersion relationship and to artifacts of the optical image processing of breaking waves.

\section{Acknowledgements}

The data were collected during the U.S. Army Corps of Engineers multi-investigator experiment, BathyDuck in Fall 2015 at the Field Research Facility (FRF), near Duck NC. We thank Jason Pipes, Brian Scarborough, Mark Priesser, Rob Mitchell, Dan Freer, Kent Hathaway, Mike Forte, and Nicholas Spore for their hard work to deploy, maintain, and retrieve the in-situ gauges, to perform nearshore bathymetric surveys, and to maintain the Argus Tower \& cameras at the FRF. We thank Dr. Rob Holman and John Stanley at Oregon State University for their expert advice on Argus and cBathy. This research was funded by the U.S. Army Corps of Engineers Coastal Field Data Collection Program, the Deputy Assistant Secretary of the Army for Research and Technology under ERDC's research program titled "Force Projection Entry Operations, STO D.GRD.2015.34", the U.S. Naval Research Laboratory base program from the Office of Naval Research, a Vannevar Bush Faculty Fellowship funded by the Assistant Secretary of Defense for Research and Engineering, and the National Science Foundation.

\section{Appendix A. Supplementary data}

Supplementary data related to this article can be found at https://doi. org/10.1016/j.coastaleng.2018.01.003.

\section{References}

Aarninkhof, S.G.J., Ruessink, B.G., Roelvink, J.A., 2005. Nearshore subtidal bathymetry from time-exposure video images. J. Geophys. Res. 110, C06011 https://doi.org/ 10.1029/2004JC002791.

Alexander, P.S., Holman, R.A., 2004. Quantification of nearshore morphology based on video imaging. Mar. Geol. 208, 101-111. https://doi.org/10.1016/ j.margeo.2004.04.017.

Bergsma, E.W.J., Conley, D.C., Davidson, M.A., O'Hare, T.J., 2016. Video-based nearshore bathymetry estimation in macro-tidal environments. Mar. Geol. 374, 31-41. https:// doi.org/10.1016/j.margeo.2016.02.001.

Birkemeier, W.A., Mason, C., 1984. The crab: a unique nearshore surveying vehicle. J. Surv. Eng 110, 1-7. https://doi.org/10.1061/(ASCE)0733-9453(1984)110:1(1).

Catálan, P.A., Haller, M.C., 2008. Remote sensing of breaking wave phase speeds with application to non-linear depth inversions. Coast Eng. 55, 93-111. https://doi.org/ 10.1016/j.coastaleng.2007.09.010.

Díaz Méndez, G.M., Haller, M.C., Raubenheimer, B., Elgar, S., Honegger, D.A., Méndez, G.M.D., Haller, M.C., Raubenheimer, B., Elgar, S., Honegger, D.A., 2015. Radar remote sensing estimates of waves and wave forcing at a tidal inlet. J. Atmos. Ocean. Technol. 32, 842-854. https://doi.org/10.1175/JTECH-D-14-00215.1.

Dugan, J.P., Vierra, K.C., Morris, W.D., Farruggia, G.J., Campion, D.C., Miller, H.C., 1999. Unique vehicles used for bathymetry surveys in exposed coastal regions. Hydro 99.

Dugan, J.P., Piotrowski, C.C., Williams, J.Z., 2001. Water depth and surface current retrievals from airborne optical measurements of surface gravity wave dispersion. J. Geophys. Res. 106, 16903. https://doi.org/10.1029/2000JC000369.

Dugan, J.P., Morris, W.D., Vierra, K.C., Piotrowski, C.C., Farruggia, G.J., Campion, D.C., 1999. Jetski-based nearshore bathymetric and current survey system on JSTOR. 
J. Coast Res. 17, 900-908. http://www.jstor.org/stable/4300249?seq=1\#page_scan_ tab_contents. (Accessed 28 July 2015).

Elgar, S., Guza, R.T., 1985a. Shoaling gravity waves: comparisons between field observations, linear theory, and a nonlinear model. J. Fluid Mech. 158, 47. https:// doi.org/10.1017/S0022112085002543.

Elgar, S., Guza, R.T., 1985b. Observations of bispectra of shoaling surface gravity waves. J. Fluid Mech. 161, 425-448.

Gallagher, E.L., Boyd, W., Elgar, S., Guza, R.T., Woodward, B., 1996. Performance of a sonar altimeter in the nearshore. Mar. Geol. 133, 241-248. https://doi.org/10.1016/ 0025-3227(96)00018-7.

Guza, R.T., Thornton, E.B., 1980. Local and shoaled comparisons of sea surface elevations, pressures, and velocities. J. Geophys. Res. 85, 1524-1530. https://doi.org/10.1029/ JC085iC03p01524.

Holland, K.T., 2001. Application of the linear dispersion relation with respect to depth inversion and remotely sensed imagery. IEEE Trans. Geosci. Rem. Sens. 39, 2060-2072. https://doi.org/10.1109/36.951097.

Holman, R.A., Stanley, J., 2007. The history and technical capabilities of Argus. Coast Eng. 54, 477-491. https://doi.org/10.1016/j.coastaleng.2007.01.003.

Holman, R., Stanley, J., 2013. cBathy bathymetry estimation in the mixed wave-current domain of a tidal estuary. J. Coast Res. 165, 1391-1396. https://doi.org/10.2112/ SI65-235.1.

Holman, R., Plant, N., Holland, T., 2013. cBathy: a robust algorithm for estimating nearshore bathymetry. J. Geophys. Res. Ocean 118, 2595-2609. https://doi.org/ 10.1002/jgrc. 20199.

Holman, R.A., Lalejini, D.M., Edwards, K., Veeramony, J., 2014. A parametric model for barred equilibrium beach profiles, 90, 85-94.

Holman, R.A., Brodie, K.L., Spore, N.J., 2017. Surf zone characterization using a small quadcopter: technical issues and procedures. IEEE Trans. Geosci. Rem. Sens. 55, 2017-2027. https://doi.org/10.1109/TGRS.2016.2635120.

hong Lee, G., Nicholls, R.J., Birkemeier, W.A., 1998. Storm-driven variability of the beach-nearshore profile at Duck, North Carolina, USA, 1981-1991. Mar. Geol. 148, 163-177. https://doi.org/10.1016/S0025-3227(98)00010-3.

Inman, D.L., Tait, R.J., Nordstrom, C.E., 1971. Mixing in the surf zone. J. Geophys. Res. 76, 3493-3514. https://doi.org/10.1029/JC076i015p03493.

Kalman, R.E., 1960. A new approach to linear filtering and prediction problems 1. Trans. ASME J. Basic Eng. 82, 35-45.

Lee, G., Birkemeier, W.A., 1993. Beach and Nearshore Survey Data: by.

Lippmann, T.C., Holman, R.A., 1989. Quantification of sand bar morphology: a video technique based on wave dissipation. J. Geophys. Res. 94, 995. https://doi.org/ 10.1029/JC094iC01p00995.

Lippmann, T.C., Holman, R.A., 1990. The spatial and temporal variability of sand bar morphology. J. Geophys. Res. 95, 11575. https://doi.org/10.1029/ JC095iC07p11575.

Ludka, B.C., Guza, R.T., O'Reilly, W.C., Yates, M.L., 2015. Field evidence of beach profile evolution toward equilibrium. J. Geophys. Res. Ocean 120, 7574-7597. https:// doi.org/10.1002/2015JC010893.

MacMahan, J., 2001. Hydrographic surveying from personal watercraft. J. Survey Eng. 127, 12-24. https://doi.org/10.1061/(ASCE)0733-9453(2001)127:1(12).

Moritz, H.R., Gelfenbaum, G.R., Kaminsky, G.M., Ruggiero, P., Oltman-Shay, J., Mckillip, D.J., 2007. Implementing regional sediment management to sustain navigation at an energetic tidal inlet. In: Coast. Sediments '07. American Society of Civil Engineers, Reston, VA, pp. 1768-1786. https://doi.org/10.1061/40926(239) 139.

Moulton, M., Elgar, S., Raubenheimer, B., 2014. A surfzone morphological diffusivity estimated from the evolution of excavated holes. Geophys. Res. Lett. 41, 4628-4636. https://doi.org/10.1002/2014GL060519.

Okamoto, T., Juana Fortes, C., Basco, D.R., 2010. Bore propagation speed at the termination of wave breaking. Coast Eng. 2010, 1-14.

Plant, N.G., Holland, K.T., Puleo, J.A., 2002. Analysis of the scale of errors in nearshore bathymetric data. Mar. Geol. 191, 71-86. https://doi.org/10.1016/S0025-3227(02) 00497-8.
Plant, N.G., Holland, K.T., Haller, M.C., 2008. Ocean wavenumber estimation from waveresolving time series imagery. IEEE Trans. Geosci. Rem. Sens. 46, 2644-2658. https://doi.org/10.1109/TGRS.2008.919821.

Postacchini, M., Brocchini, M., 2014. A wave-by-wave analysis for the evaluation of the breaking-wave celerity. Appl. Ocean Res. 46, 15-27. https://doi.org/10.1016/ j.apor.2014.01.005.

Radermacher, M., Wengrove, M., van Thiel de Vries, J., Holman, R., 2014. Applicability of video-derived bathymetry estimates to nearshore current model predictions. J. Coast Res. 70, 290-295. https://doi.org/10.2112/SI70-049.1.

Raubenheimer, B., Guza, R.T., Elgar, S., 1996. Wave transformation across the inner surf zone. J. Geophys. Res. Ocean 101, 25589-25597. https://doi.org/10.1029/ 96JC02433.

Ruggiero, P., Kaminsky, G.M., Gelfenbaum, G., Cohn, N., 2016. Morphodynamics of prograding beaches: a synthesis of seasonal- to century-scale observations of the Columbia River littoral cell. Mar. Geol. 376, 51-68. https://doi.org/10.1016/ j.margeo.2016.03.012.

Rutten, J., de Jong, S.M., Ruessink, G., 2017. Accuracy of nearshore bathymetry inverted from $\$\{X\} \$$-band radar and optical video data. IEEE Trans. Geosci. Rem. Sens. 55, 1106-1116. https://doi.org/10.1109/TGRS.2016.2619481.

Sallenger, A.H., Holman, R.A., 1985. Wave energy saturation on a natural beach of variable slope. J. Geophys. Res. 90, 11939. https://doi.org/10.1029/ JC090iC06p11939.

Smith, J.M., Bak, S., Hesser, T., Bryant, M.A., Massey, C., 2017. FRF wave test bed and bathymetry inversion. Coast. Eng. Proc. 1, 22. https://doi.org/10.9753/ icce.v35.waves.22.

Stockdon, H.F., Holman, R.A., 2000. Estimation of wave phase speed and nearshore bathymetry from video imagery. J. Geophys. Res. 105, 22015. https://doi.org/ 10.1029/1999JC000124.

Suhayda, J.N., Pettigrew, N.R., 1977. Observations of wave height and wave celerity in the surf zone. J. Geophys. Res. 82, 1419-1424. https://doi.org/10.1029/ JC082i009p01419.

Sun, C., 2002. Fast stereo matching using rectangular subregioning and 3D maximumsurface techniques. Int. J. Comput. Vis. 47, 99-117. https://doi.org/10.1023/A: 1014585622703.

Svendsen, I.A., Qin, W., Ebersole, B.A., 2003. Modelling waves and currents at the LSTF and other laboratory facilities. Coast Eng. 50, 19-45. https://doi.org/10.1016/ S0378-3839(03)00077-2.

Thornton, E.B., Guza, R.T., 1982. Energy saturation and phase speeds measured on a natural beach. J. Geophys. Res. Ocean 87, 9499-9508. https://doi.org/10.1029/ JC087iC12p09499.

Tissier, M., Bonneton, P., Almar, R., Castelle, B., Bonneton, N., Nahon, A., 2011. Field measurements and non-linear prediction of wave celerity in the surf zone. Eur. J. Mech. B Fluid 30, 635-641. https://doi.org/10.1016/j.euromechflu.2010.11.003.

van Dongeren, A., Plant, N., Cohen, A., Roelvink, D., Haller, M.C., Catalán, P., 2008. Beach Wizard: nearshore bathymetry estimation through assimilation of model computations and remote observations. Coast Eng. 55, 1016-1027. https://doi.org/ 10.1016/j.coastaleng.2008.04.011.

van Enckevort, I.M.J., Ruessink, B.G., 2001. Effect of hydrodynamics and bathymetry on video estimates of nearshore sandbar position. J. Geophys. Res. Ocean 106, 16969-16979. https://doi.org/10.1029/1999JC000167.

Wengrove, M., Henriquez, M., 2013. Monitoring morphology of the Sand Engine leeside using Argus' cBathy. Dyn. 2013 7th http://repository.tudelft.nl/islandora/object/ uuid:fe4b009f-3c35-49c9-87e0-e0ee24517dd0? collection=research. (Accessed 25 July 2017).

Wilson, G.W., Özkan-Haller, H.T., Holman, R. a., 2010. Data assimilation and bathymetric inversion in a two-dimensional horizontal surf zone model. J. Geophys. Res. Ocean 115, 1-17. https://doi.org/10.1029/2010JC006286.

Wilson, G.W., Özkan-Haller, H.T., Holman, R.A., Haller, M.C., Honegger, D.A., Chickadel, C.C., 2014. Surf zone bathymetry and circulation predictions via data assimilation of remote sensing observations. J. Geophys. Res. Ocean 119, 1993-2016. https://doi.org/10.1002/2013JC009213. 